\title{
COMPARISON OF SOLID ROCKET MOTOR THRUST MODULATION TECHNIQUES
}

\author{
by \\ Clayton Edward Wozney \\ Bachelor of Engineering, Ryerson University (2013) \\ Bachelor of Science, Brandon University (1987)
}

\author{
A thesis \\ presented to Ryerson University \\ in partial fulfillment of the \\ requirements for the degree of \\ Master of Applied Science \\ in the program of \\ Aerospace Engineering
}

Toronto, Ontario, Canada, 2017

(c) Clayton Wozney 2017 


\section{AUTHOR'S DECLARATION FOR ELECTRONIC SUBMISSION OF A THESIS}

I hereby declare that I am the sole author of this thesis. This is a true copy of the thesis, including any required final revisions, as accepted by my examiners.

I authorize Ryerson University to lend this thesis to other institutions or individuals for the purpose of scholarly research.

I further authorize Ryerson University to reproduce this thesis by photocopying or by other means, in total or in part, at the request of other institutions or individuals for the purpose of scholarly research.

I understand that my thesis may be made electronically available to the public. 


\title{
COMPARISON OF SOLID ROCKET MOTOR \\ THRUST MODULATION TECHNIQUES
}

Clayton Wozney, Aerospace Engineering, MASc, Ryerson University, 2017

\begin{abstract}
The thrust profiles of solid rocket motors are usually determined ahead of time by propellant composition and grain design. Traditional techniques for active thrust modulation use a moveable pintle to dynamically change the nozzle throat diameter, increasing the chamber pressure and therefore thrust. With this approach, high chamber pressures must be endured with only modest increases in thrust. Alternatively, it has been shown that spinning a solid rocket motor on its longitudinal axis can increase the burning rate of the propellant and therefore the thrust without the resulting high chamber pressures. Building on prior experience modelling pressuredependent, flow-dependent and acceleration-dependent burning in solid rocket motors, an internal ballistic simulation computer program is modified for the present study where the use of the pintle nozzle and spin-augmented solid rocket motor combustion approaches, for a reference cylindrical-grain motor, are compared. This study confirms that comparable thrust augmentation can be gained at lower chamber pressures using the novel spin-acceleration approach, relative to the established pintle-nozzle approach, thus potentially providing a significant design advantage.
\end{abstract}




\section{Acknowledgements}

I would like to thank Dr. David Greatrix for all of his patience and guidance during the research and writing of this thesis, and Mr. Jerry Karpynczyk and Mr. Peter Bradley for their moral support and constant enthusiasm for the project. 


\section{Dedication}

I dedicate this master's thesis to my wonderful and ever-supportive wife Deidra, whose constant encouragement and personal sacrifice allowed me to complete this endeavour. 


\section{Table of Contents}

$\begin{array}{ll}\text { Abstract } & \text { iii }\end{array}$

Acknowledgements $\quad$ iv

Dedication $\quad$ v

List of Tables $\quad$ ix

List of Figures $\quad$ X

Nomenclature $\quad$ xii

1 Introduction 1

2 Solid Propellant Burning Rate Models $\quad 7$

2.1 Pressure Dependent Burning . . . . . . . . . . . . . . . . 9

2.2 Erosive Burning . . . . . . . . . . . . . . . . . . . 10

2.3 Acceleration Effects on Burning Rate . . . . . . . . . . . . . . . . 13

3 Thrust Modulation of Solid Rocket Motors 20

3.1 Burning Rate Augmentation Due to Increased

Chamber Pressure. . . . . . . . . . . . . . . 20 
3.2 Burning Rate Augmentation Due to Normal Acceleration . . . . . . . 22

3.3 Acceleration Effects in Metallized and

Non-Metallized Propellants . . . . . . . . . . . . . . . . 23

3.4 Effects of Orientation Angle on Acceleration Effects . . . . . . . . . . 24

4 Internal Ballistic Modelling and Analysis $\quad 26$

4.1 Equations of Motion . . . . . . . . . . . . . 26

4.1.1 Gas Phase .................... 26

4.1.2 Particle Phase . . . . . . . . . . . . . . . . . . 27

4.2 Computer Modelling of Internal Ballistics . . . . . . . . . . . . . . . 28

4.3 Reference Motor . . . . . . . . . . . . . . . . . . . . . 28

5 Simulation Results $\quad 31$

5.1 Reference Motor . . . . . . . . . . . . . . . . . 31

5.2 Pintle Nozzle Motor . . . . . . . . . . . . . . . . . . . . 34

5.3 Spinning Rocket Motor . . . . . . . . . . . . . . . 36

5.4 Comparison of Pintle Nozzle and Spinning SRM . . . . . . . . . . . 37

5.5 Spinning Rocket at Maximum Chamber

Pressure ............................... 40

5.6 Spinning Rocket With Longitudinal

Acceleration ....................... . . . . 43

6 Discussion of Results 48

6.1 Implementation Strategies for a Spinning SRM . . . . . . . . . . . 50 
7 Conclusion

8 Considerations for Future Work

References 


\section{List of Tables}

1.1 Characteristics of various solid propellants . . . . . . . . . . . . 2

4.1 Summary of the reference solid rocket motor simulation parameters . 30

5.1 Summary of the simulation results . . . . . . . . . . . . . . . 44 


\section{List of Figures}

1.1 Structural features found on solid rocket motors . . . . . . . . . . . 3

1.2 Thrust profiles from various grain geometries . . . . . . . . . . . 4

1.3 Cutaway diagram of a finocyl propellant grain in an SRM . . . . . . . 5

2.1 Pressure-dependant burning rate behaviour . . . . . . . . . . . . . . 10

2.2 Schematic diagram of combustion zone stretching . . . . . . . . . . 12

2.3 Theoretical and experimental data for burning rate augmentation . . 13

2.4 Burning rate augmentation as a function of normal acceleration . . . 15

2.5 Burning rate augmentation as a function of resultant acceleration angle 16

2.6 Head-end pressure-time profiles of solid rocket motor, baseline . . . . 17

2.7 Head-end pressure-time profiles of solid rocket motor, 15g . . . . . . 18

2.8 Sea-level thrust-time profiles of solid rocket motor, $15 \mathrm{~g} \ldots \ldots$. . . . . 19

3.1 Moveable pintle varying the throat area of the nozzle . . . . . . . 21

3.2 SRM spinning as a means of inducing a normal acceleration field . . . 23

3.3 Schematic diagram of acceleration vectors acting near the propellant

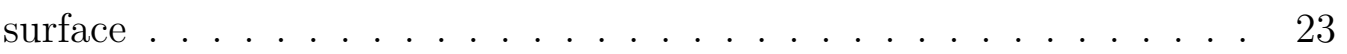

5.1 Chamber pressure-time profile for reference motor firing . . . . . . . . 32

5.2 Sea-level thrust-time profile for reference motor firing . . . . . . . . 33 
5.3 Chamber pressure-time profile for pintle motor firing . . . . . . . . . 34

5.4 Thrust-time profile for pintle motor firing . . . . . . . . . . . 35

5.5 Chamber pressure-time profile for spinning motor firing, 10 rps . . . . 36

5.6 Sea-level thrust-time profile for spinning motor firing, 10 rps . . . . . 37

5.7 Chamber pressure-time profiles for all motor firings . . . . . . . . . . 38

5.8 Sea-level thrust-time profiles for all motor firings . . . . . . . . . . . . 39

5.9 Sea-level chamber pressure-time profile for spinning rocket motor firing,

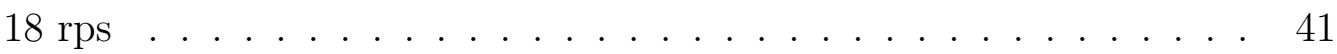

5.10 Sea-level thrust-time profile for spinning rocket motor firing, 18 rps . 42

5.11 Seal-level chamber pressure-time profile for spinning rocket motor firing with lateral acceleration . . . . . . . . . . . . . 44

5.12 Sea-level thrust-time profile for spinning rocket motor firing with longitudinal acceleration ........................... . . 45

5.13 Sea-level chamber pressure-time profile for boosted spin rate . . . . . 46

5.14 Sea-level thrust-time profile for boosted spin rate . . . . . . . . . . . 47

6.1 Variable incident tail fins for inducing spin . . . . . . . . . . . . . . 51

6.2 Cutaway of spinning rocket with SRM rotated independently of the

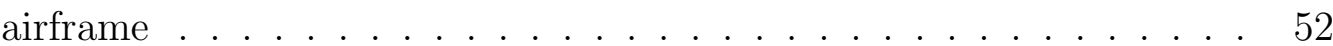

6.3 Cutaway of externally spun SRM rotated independently of the airframe on the launch pad . . . . . . . . . . . . . . . . 53

6.4 Schematic of an externally spun rocket airframe . . . . . . . . . . 54 


\section{Nomenclature}

\section{Symbols}

$A_{e} \quad$ Nozzle exit plane cross-sectional area, $\mathrm{m}^{2}$

$A_{t} \quad$ Nozzle throat cross-sectional area, $\mathrm{m}^{2}$

$a_{l} \quad$ Longitudinal (or lateral) acceleration, $\mathrm{m} \mathrm{s}^{-2}$

$a_{n} \quad$ Normal acceleration, $\mathrm{ms}^{-2}$

$C \quad$ de St. Robert's law coefficient, $\mathrm{m} \mathrm{s}^{-1} \mathrm{~Pa}^{-\mathrm{n}}$

$C_{F} \quad$ Thrust coefficient [rocket engine]

$C_{o} \quad$ de St. Robert's law coefficient, reference conditions, $\mathrm{m} \mathrm{s}^{-1} \mathrm{~Pa}^{-\mathrm{n}}$

$C_{p} \quad$ Constant-pressure specific heat, gas phase, $\mathrm{J} \mathrm{kg}^{-1} \mathrm{~K}^{-1}$

$C_{s} \quad$ Specific heat, solid phase, $\mathrm{J} \mathrm{kg}^{-1} \mathrm{~K}^{-1}$

$C_{F, v} \quad$ Vacuum thrust coefficient

D Aerodynamic drag, N

$d_{m} \quad$ Particle mean diameter $\mathrm{m}$

$d_{p} \quad$ Port diameter, $\mathrm{m}$

f Darcy-Weisbach friction factor

$f^{*} \quad$ Zero-transpiration friction factor

$f_{\text {lim }} \quad$ Limit friction factor for negative erosive burning

G Axial mass flux, $\mathrm{kg} \mathrm{m}^{-2} \mathrm{~s}^{-1}$

$G_{a} \quad$ Accelerative mass flux, $\mathrm{kg} \mathrm{m}^{-2} \mathrm{~s}^{-1}$ 


\begin{tabular}{|c|c|}
\hline$\Delta H_{s}$ & Net surface heat release, $\mathrm{J} \mathrm{kg}^{-1}$ \\
\hline$h$ & Effective convective heat transfer coefficient, $\mathrm{W} \mathrm{m}^{-2} \mathrm{~K}^{-1}$ \\
\hline$h^{*}$ & Zero-transpiration convective heat transfer coefficient, $\mathrm{W} \mathrm{m}^{-2} \mathrm{~K}^{-1}$ \\
\hline$K$ & $\begin{array}{l}\text { Lateral/longitudinal acceleration burning rate displacement orientation } \\
\text { angle coefficient }\end{array}$ \\
\hline$K_{\delta}$ & Shear layer coefficient, $\mathrm{m}^{-1}$ \\
\hline$k$ & Gas thermal conductivity, $\mathrm{W} \mathrm{m}^{-1} \mathrm{~K}^{-1}$ \\
\hline$M$ & Atomic mass unit, amu \\
\hline$\dot{m}_{e}$ & Mass flow through the nozzle exit, $\mathrm{kg} \mathrm{s}^{-1}$ \\
\hline$\dot{m}_{t}$ & Mass flow through the nozzle throat, $\mathrm{kg} \mathrm{s}^{-1}$ \\
\hline$n$ & Pressure-dependent burning rate exponent \\
\hline$p_{e}$ & Nozzle exit static pressure, $\mathrm{Pa}$ \\
\hline$p_{\infty}$ & Outside ambient air pressure, $\mathrm{Pa}$ \\
\hline$Q$ & Heat transfer rate, $\mathrm{W}$ \\
\hline $\mathrm{R}$ & Specific gas constant, $\mathrm{J} \mathrm{kg}^{-1} \mathrm{~K}^{-1}$ \\
\hline $\operatorname{Re}_{d}$ & Local gas Reynold's number based on core hydraulic diameter \\
\hline$r_{b}$ & Overall burning rate, $\mathrm{ms}^{-1}$ \\
\hline$r_{e}$ & Erosive burning rate positive component, $\mathrm{ms}^{-1}$ \\
\hline$r_{o}$ & Base burning rate, $\mathrm{m} \mathrm{s}^{-1}$ \\
\hline$r_{p}$ & Pressure-dependent burning rate, $\mathrm{m} \mathrm{s}^{-1}$ \\
\hline$S_{p}$ & Propellant surface area, $\mathrm{m}^{2}$ \\
\hline$T_{f}$ & Flame temperature, $\mathrm{K}$ \\
\hline$T_{i}$ & Initial temperature, solid phase, $\mathrm{K}$ \\
\hline
\end{tabular}


$T_{s} \quad$ Burning surface temperature, $\mathrm{K}$

$T_{i o} \quad$ Initial temperature, solid phase, reference conditions, $\mathrm{K}$

$u_{e} \quad$ Nozzle exit gas or exhaust jet velocity, $\mathrm{m} \mathrm{s}^{-1}$

$u_{\text {eff }} \quad$ Effective gas velocity parallel to propellant surface, $\mathrm{m} \mathrm{s}^{-1}$

$u_{\infty} \quad$ Bulk axial gas velocity, $\mathrm{m} \mathrm{s}^{-1}$

$v_{f} \quad$ Normal gas flow velocity of flame, $\mathrm{m} \mathrm{s}^{-1}$

$\alpha_{p} \quad$ Particle mass loading fraction

$\delta_{o} \quad$ Reference energy zone thickness, $\mathrm{m}$

$\delta_{r} \quad$ Resultant energy zone thickness, $\mathrm{m}$

$\epsilon \quad$ Effective propellant surface roughness height, $\mathrm{m}$

$\gamma \quad$ Ratio of specific heats of gas

$\mu \quad$ Absolute [dynamic] gas viscosity, $\mathrm{kg} \mathrm{m}^{-1} \mathrm{~s}^{-1}$

$\phi \quad$ Acceleration vector angle, ${ }^{\circ}$

$\phi_{d} \quad$ Acceleration vector displacement orientation angle, ${ }^{\circ}$

$\rho \quad$ Local gas density, $\mathrm{kg} \mathrm{m}^{-3}$

$\rho_{p} \quad$ Density, particles within gas flow volume, $\mathrm{kg} \mathrm{m}^{-3}$

$\rho_{s} \quad$ Density, solid phase, $\mathrm{kg} \mathrm{m}^{-3}$

$\sigma_{p} \quad$ Pressure-dependant burning rate temperature sensitivity, $\mathrm{K}^{-1}$

$\Theta_{r} \quad$ Resultant angle of stretched energy zone, ${ }^{\circ}$

\section{Acronyms}

AP Ammonium perchlorate, (crystalline oxidizer)

CTPB Carboxy-terminated polybutadiene (solid fuel)

EPON Epoxy resin 
MN Mega-Newton

NC Nitrocellulose, (solid monopropellant)

NG Nitroglycerine, (liquid monopropellant/explosive; solid when combined with NC)

PBAA Polybutadiene acrylic acid (solid fuel)

PBAN Polybutadiene-acrylic acid-acrylonitrile terpolymer (solid fuel)

PS Polysulfide

PU Polyurethane

QUROC QUasi-steady ROCket (code)

SRM Solid propellant rocket motor 


\section{Introduction}

A solid propellant rocket motor (SRM) is nominally one of the simpler chemical rocket propulsion systems. Often with no moving parts, SRMs can be very straightforward to operate; that is, once ignited, the SRM burns to completion based on its physical and chemical characteristics as defined at the time of design and manufacture without any dynamic throttle or thrust control. SRMs range in thrust delivery from $\mu \mathrm{N}$ thrusters on mini-satellites to $\mathrm{MN}$ class boosters for space launch vehicles [1]. For single burn applications, they are often the most cost-effective propulsion system among various alternatives (e.g., liquid or hybrid rocket engines).

The nominal performance of solid rocket motors is determined primarily by their propellant constituents, formulation and grain geometry. The propellant formulations of SRMs typically consist of a fuel, oxidizer, binder, and optionally various small quantities of combustion modifiers. Table 1.1 [1] shows some common combinations of fuel and oxidizers used in operational SRMs. A typical SRM consists of one or more propellant grains, cast or assembled into a thin casing capable of withstanding the intended combustion pressures, closed at one end with a divergent or convergent-divergent nozzle at the other end as shown in Fig. $1.1[2]^{1}$.

To prevent the casing material from being exposed to the high combustion tem-

\footnotetext{
${ }^{1}$ The thrust termination opening device shown is something often used on large SRMs which allows the thrust of the SRM to be immediately cut off by essentially blowing the front end of the SRM off. This gives the flight control system a one-shot ability to dynamically (and dramatically) control the thrust profile and firing time to more accurately place a payload or munition.
} 
Table 1.1: Characteristics of various solid propellants at nominal operating conditions ${ }^{b}$

\begin{tabular}{lcccccc}
\hline & $\rho_{s}$ & $T_{f}$ & $T_{S}$ & $M$ & & $r_{b}$ \\
Propellant $^{a}$ & $\left(\mathrm{~kg} \mathrm{~m}^{-3}\right)$ & $(\mathrm{K})$ & $(\mathrm{K})$ & $(\mathrm{amu})$ & $\gamma$ & $\left(\mathrm{m} \mathrm{s}^{-1}\right)$ \\
\hline NC/NG & 1630 & 2300 & 760 & 22 & 1.26 & 0.007 \\
AP/PS/additives & 1635 & 2500 & 780 & 25 & 1.23 & 0.008 \\
AP/PU/additives & 1620 & 2400 & 670 & 21 & 1.25 & 0.005 \\
AP/PBAA/EPON & 1600 & 2300 & 700 & 22 & 1.24 & 0.008 \\
AP/PBAN/Al & 1750 & 2600 & 800 & 24 & 1.24 & 0.010 \\
AP/CTPB/additives & 1600 & 2300 & 800 & 22 & 1.25 & 0.011 \\
AP/HTPB/Al & 1750 & 3050 & 950 & 26 & 1.21 & 0.011 \\
\hline
\end{tabular}

${ }^{a} \mathrm{Al}$, aluminum; AP, ammonium perchlorate; CTPB, carboxy-terminated polybutadiene; EPON, epoxy resin; HTPB, hydroxyl-terminated polybutadiene; NC, nitrocellulose; NG, nitroglcyerine; PBAA, polybutadiene-acrylic acid polymer; PBAN, polybutadiene-acrylic acid-acrylonitrile terpolymer; PS, polysulfide; PU, polyurethane

${ }^{b} 6.89 \mathrm{MPa}$ chamber pressure; values are typical, although may vary depending on the given propellant formulation 
Figure 1.1: Structural features found on solid rocket motors

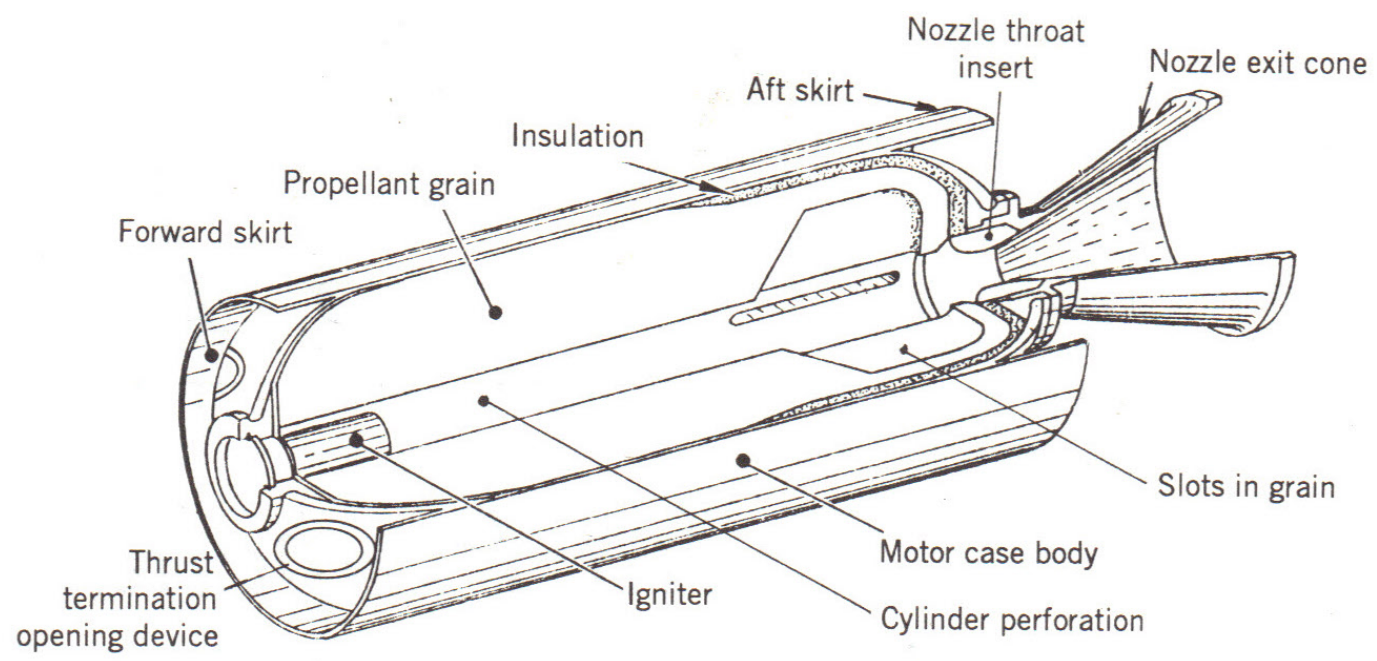

peratures for the entire duration of the mission, unless the motor burn duration is very short or the case is unusually robust or well insulated, the motors are usually manufactured with a central hollow core and the propellant burns from the inside outward. The amount of thrust available at any particular point in the firing of an SRM is highly dependent on the exposed area of propellant surface burning at that point in time. Various central core geometries allow different thrust profiles to be created, some examples of which are shown in Fig. 1.2.

During firing, the burning surface is regressing (as ambient-temperature propellant is converted into the high-temperature, high-pressure gas and combustion byproducts of deflagration) in a direction normal to the burning surface. A cylindrical core perforation will gradually expose more propellant surface area and as shown in Fig. 1.2a the instantaneous thrust will increase during the duration of the burn. 
Figure 1.2: Thrust profiles from various grain geometries

(a)

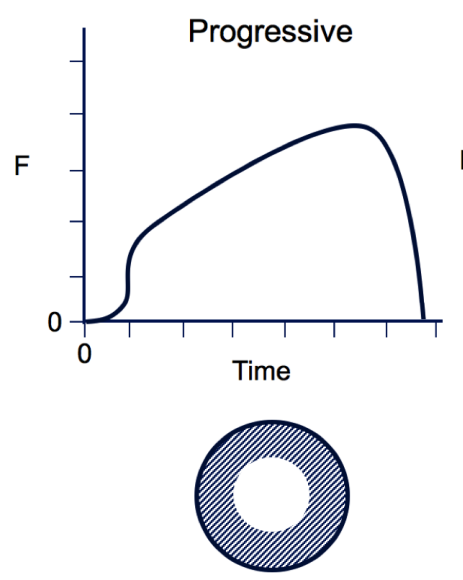

(b)
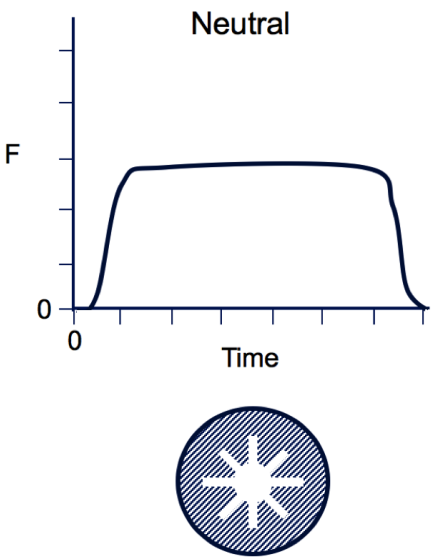

(c)

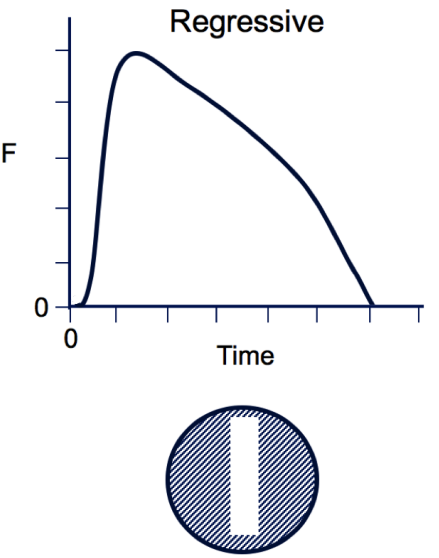

This is not always desirable because at the same time that thrust is increasing the mass of the flight vehicle is decreasing (as propellant is burned away) so the longitudinal acceleration on the flight vehicle increases significantly. In addition, the simple cylindrical core has the lowest burning surface area (and lowest thrust) right after ignition when conversely one would commonly want the most thrust early on.

The star grain profile as shown in Fig. 1.2b has a number of fins or slots (typically) molded into the propellant grain, giving a larger surface area available at the beginning of the firing which contributes to a high initial thrust, but then as the web of the star grain is consumed, the core starts to evolve towards a cylindrical shape. By carefully matching the size and length of the star grain profile to the burn rate of the propellant, a flat or neutral thrust-time curve can be produced. It is also quite common to have only one part of the fuel grain molded with extra propellant surface-exposing fins or slots, with the remainder a simple cylindrical bore. Such 
configurations are called finocyl (fin + cylinder) and are often found in the upperstage motors of multi-stage launch vehicles [1], providing a neutral thrust profile especially in SRM casing designs which are not cylindrical as shown in Fig. 1.3 [2].

Figure 1.3: Cutaway diagram of a finocyl propellant grain in an SRM showing the combination of a cylindrical central port and a star grain plus radial slots or fins cast into the forward section of the propellant grain

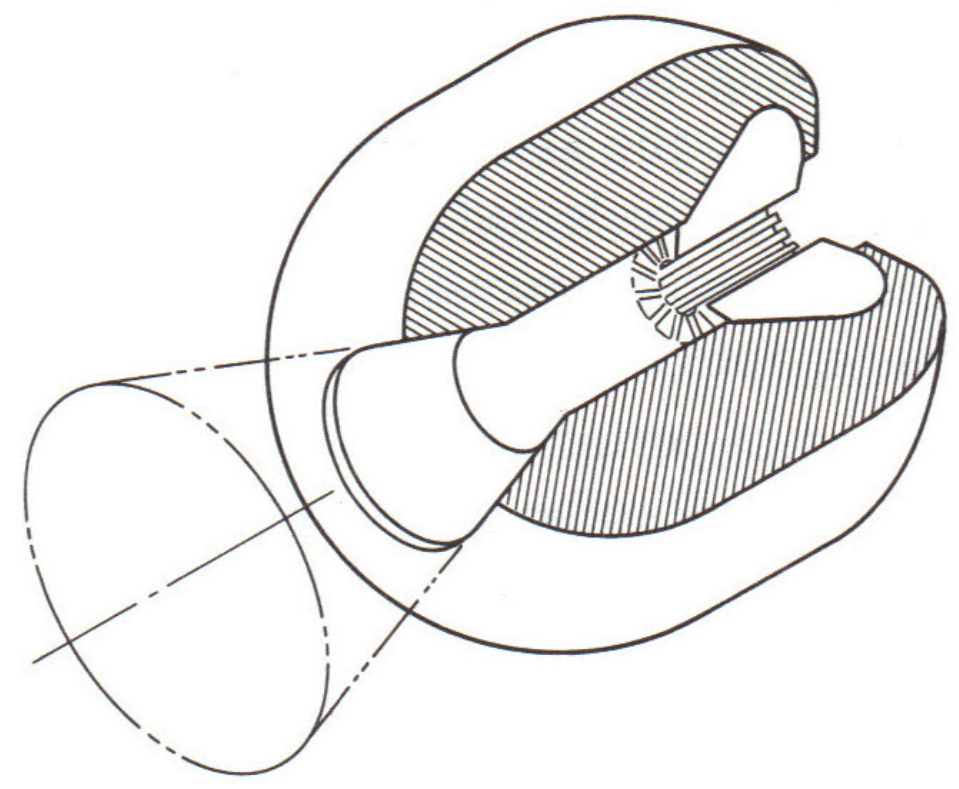

Finally, the third profile in Fig. 1.2c features a slot profile which will give a fairly high initial surface area but as the firing progresses, the propellant area is reduced and the thrust profile shows a regressive curve. Such a thrust profile provides a high initial thrust to quickly accelerate the flight vehicle at launch and then the regressive thrust curve combines with the steady reduction in propellant mass over the duration of the firing to produce a more neutral acceleration curve. 
In all cases shown this far, the thrust profile is fixed at the time of SRM manufacture or assembly but, because of real-time requirements (e.g. last minute payload changes, maneuvering requirement, interception), it is desirable on occasion that the SRM thrust be able to be modulated on command during parts of the flight. The remainder of this thesis will examine the factors that affect the instantaneous propellant burning rate, investigate various ways to modify that burning rate, and compare and contrast some of the design and engineering tradeoffs between the two techniques that one may consider for thrust modulation. 


\section{Solid Propellant Burning Rate Models}

The thrust of any chemical rocket can be ideally calculated by [1]

$$
F=\dot{m}_{e} u_{e}+\left(p_{e}-p_{\infty}\right) A_{e}
$$

Assuming that the nozzle is choked and that no mass injection occurs, from gas dynamics the mass flow through the exit of the nozzle is the same as the mass flow through the exhaust nozzle throat as described by

$$
\dot{m}_{t}=\dot{m}_{e}=\left[\frac{\gamma}{R T_{F}}\left(\frac{2}{\gamma+1}\right)^{\frac{\gamma+1}{\gamma-1}}\right]^{1 / 2} A_{t} p_{c}
$$

From this equation we can see that if the nozzle throat area $A_{t}$ is reduced and the mass flow remains the same, the chamber pressure $p_{c}$ will inevitably increase. From the base pressure-dependent burning rate of the propellant, $r_{p}$, and the propellant solid density, $\rho_{p}$, the instantaneous mass flow rate $\dot{m}_{e}$ in this simplified scenario can also be determined by

$$
\dot{m}_{e}=r_{p} \rho_{p} S_{p}
$$


where $S_{p}$ is the area of the burning propellant surface. It is also possible to calculate the motor thrust with an ideal or underexpanded choked nozzle directly from the ratio of the chamber pressure and the nozzle exit pressure $p_{e}$ via

$$
F=C_{F, v}\left[1-\left(\frac{p_{e}}{p_{c}}\right)^{\frac{\gamma-1}{\gamma}}\right]^{1 / 2} A_{t} p_{c}+\left(p_{e}-p_{\infty}\right) A_{e}
$$

where $C_{F, v}$ is the vacuum coefficient of thrust as calculated by

$$
C_{F, v}=\left[\frac{2 \gamma^{2}}{\gamma-1}\left(\frac{2}{\gamma+1}\right)^{\frac{\gamma+1}{\gamma-1}}\right]^{1 / 2}
$$

which is a function of the gas ratio of specific heats of the combustion gases [1].

The performance of a solid rocket motor is initially dependent on the nominal or base pressure-dependent burning rate $r_{p}$ of the propellant composition itself but this burn rate can be influenced in various other ways during the firing cycle. It is well known $[1,3,4,6,8]$ that the burning rate of solid rocket propellant is affected by the following three factors:

1. Chamber pressure (pressure-dependent burning)

2. Axial mass flux (erosive burning)

3. Normal acceleration 


\subsection{Pressure Dependent Burning}

The burning rate $r_{p}$ of most solid propellants exhibits a dependence on the local static pressure, governed by de St. Robert's or Vieille's empirical law [1]:

$$
r_{p}=C p^{n}
$$

where $C$ and $n$ are determined empirically by various test firings at different chamber

pressures $p_{c}$. The exponent $n$ is in the range of 0.2 to 0.5 and coefficient $C$ is sensitive to the propellant's initial starting temperature $T_{i}$ :

$$
C=C_{o} \exp \left[\sigma_{p}\left(T_{i}-T_{i o}\right)\right]
$$

where $C_{o}$ and $T_{i o}$ are at reference conditions, for example, standard sea-level values, and $\sigma_{p}$ is the pressure-dependent burning-rate temperature sensitivity coefficient, which can range from 0.001 to $0.009 \mathrm{~K}^{-1}$. Initial starting temperatures significantly below nominal for the propellant formulation will reduce $C$ and therefore lead to a reduction in $r_{p}$ which can result in a lower chamber pressure $p_{c}$, potentially leading to combustion instabilities and reduced thrust [1].

For conventional propellants, plotting burning-rate versus chamber pressure results in a straight line profile on a log-log graph as show in Figure 2.1. The pressuredependent burning-rate behaviour for other solid propellant categories can be different from the conventional profile. Some propellants can display a plateau characteristic where the burning rate remains relatively constant over a range of pressures. 
Others display a mesa profile where the burning rate can initially rise and remain steady like a plateau-type propellant before exhibiting a decrease in burn rate while the chamber pressure continues to increase. The investigations in this thesis will focus on propellants exhibiting conventional pressure-dependent behaviour.

Figure 2.1: Pressure-dependant burning rate behaviour of three propellant categories

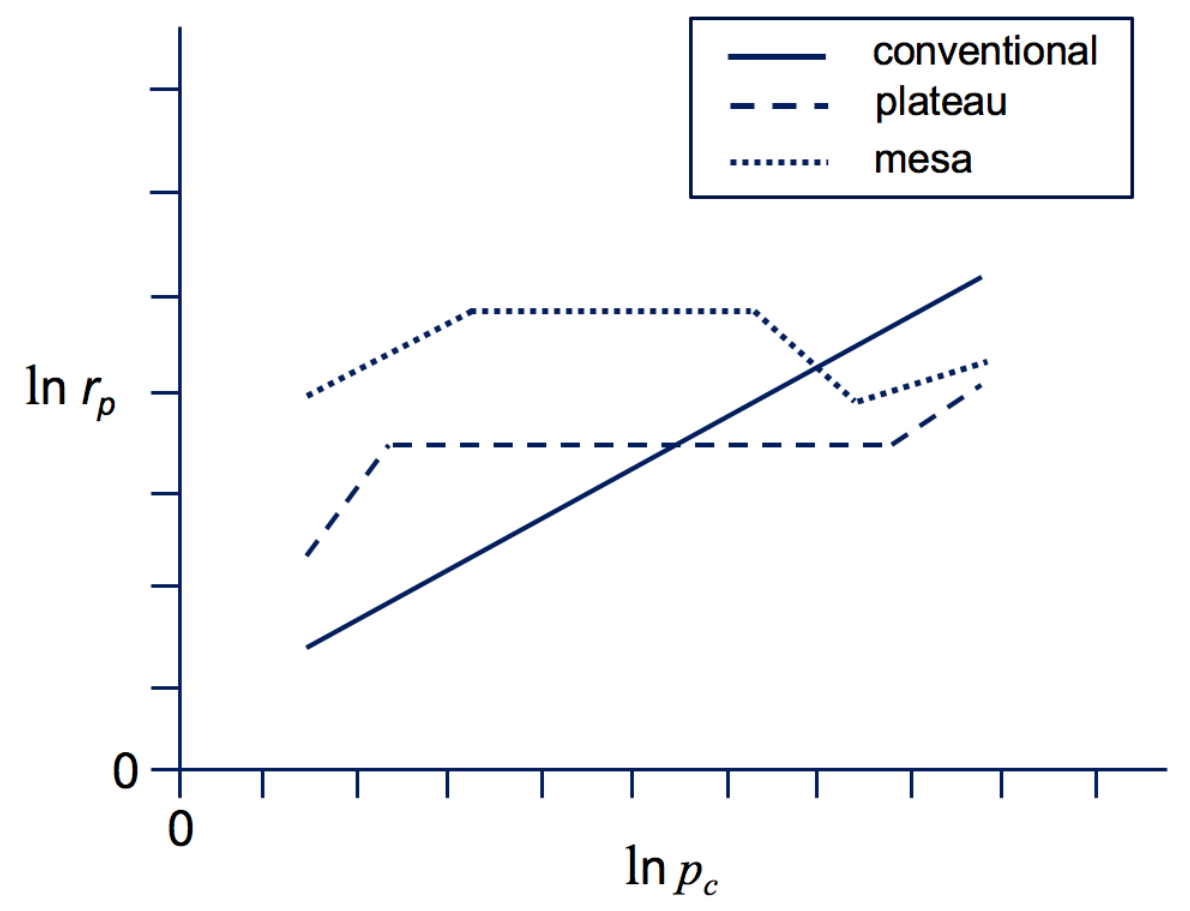

\subsection{Erosive Burning}

Positive erosive burning is an augmentation of the base burning rate due to the heightened convective heat transfer from the predominantly turbulent flow over the burning surface of the propellant [1]. The erosive burning component $r_{e}$ can be 
estimated from the Greatrix and Gottlieb convective heat transfer feedback model $[1,3,8]:$

$$
r_{e}=\frac{h\left(T_{F}-T_{s}\right)}{\rho_{s}\left[C_{s}\left(T_{s}-T_{i}\right)-\Delta H_{s}\right]}
$$

where the convective heat transfer coefficient $h$ under transpiration, assuming turbulent flow corrected for compressibility, is described by

$$
h=\frac{\rho_{s} r_{b} C_{p}}{\exp \left(\frac{\rho_{s} r_{h} C_{p}}{h^{*}}\right)-1}
$$

with $h^{*}$ calculated as a function of the zero-transpiration Darcy-Weisbach friction factor $f^{*}$ and axial mass flux $G$ from

$$
h^{*}=\frac{k^{2 / 3} C_{p}^{1 / 3}}{\mu^{2 / 3}} \frac{G f^{*}}{8}
$$

where the value of $f^{*}$ may be found for fully developed turbulent flow using Colebrook's expression

$$
\left(f^{*}\right)^{-1 / 2}=-2 \log _{10}\left[\frac{2.51}{\operatorname{Re}_{d}\left(f^{*}\right)^{1 / 2}}+\frac{\epsilon / d_{p}}{3.7}\right]
$$

In some experiments, the burning rate appears to drop below the expected value at lower flow speeds and recover at higher core flow speeds. This effect is known as negative erosive burning and Greatrix [1] has proposed that this phenomenon may be due to laminar-type stretching of the of the effective combustion zone height with the local core flow as shown in Fig. 2.2. Extending Eq. 2.8 to include the burning rate 
reduction caused by this stretching of the combustion zone height gives an overall burning rate of

$$
r_{b}=\left.\frac{r_{b}}{r_{o}}\right|_{\delta_{r}} \cdot r_{o}+r_{e}
$$

where via Greatrix's analysis [1]:

$$
\left.\frac{r_{b}}{r_{o}}\right|_{\delta_{r}}=\cos \left[\tan ^{-1}\left(\frac{u_{e f f}}{v_{f}}\right)\right]=\cos \left[\tan ^{-1}\left(K_{\delta} \delta_{o}\left[1-\left(f / f_{\text {lim }}\right)^{1 / 2}\right] \frac{\rho u_{\infty}}{\rho_{s} r_{o}}\right)\right], f<f_{\text {lim }}
$$

Figure 2.2: Schematic diagram of combustion zone stretching

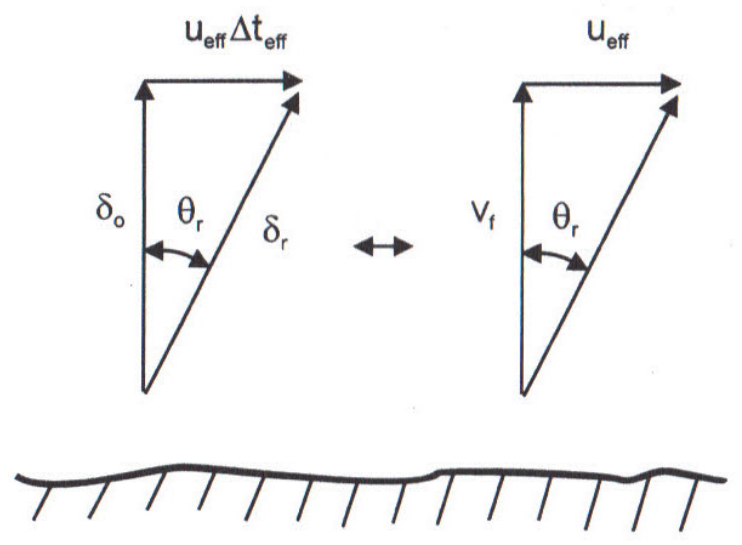

In this case, $\delta_{r}$ is the effective thickness of the stretched combustion zone under core flow relative to the base thickness $\delta_{o}$ under pressure-dependent burning only. Fig. 2.3 is an an example of this negative erosive burning effect manifesting early in the firing while the flow speed within the core is fairly low and the flow is laminar [1]. The effect appears to largely disappear at higher flow speeds as the flow becomes more turbulent and positive erosive burning dominates. 
Figure 2.3: Theoretical and experimental data for burning rate augmentation as a function of mass flux

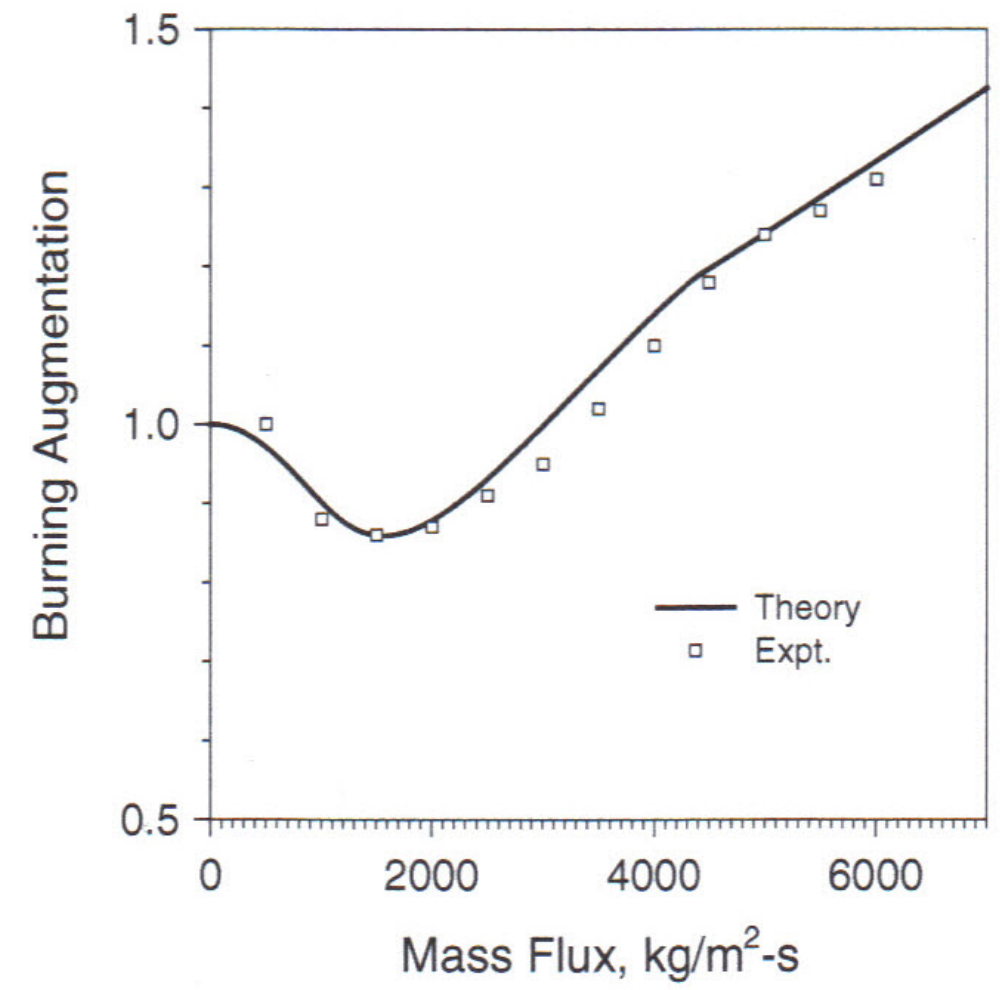

\subsection{Acceleration Effects on Burning Rate}

Due to radial vibration or spinning along the SRM's longitudinal axis, normal acceleration $a_{n}$ may act to augment the burning rate of the solid propellant [13$15,17,22,23]$. Greatrix $[1,3,6]$ has put forward a generalized model that represents the combustion zone as being compressed (i.e. the effective flame height is reduced) under a normal acceleration field. This compression results in an augmentation of 
the propellant burning rate according to

$$
r_{b}=\left[\frac{C_{p}\left(T_{F}-T_{s}\right)}{C_{s}\left(T_{s}-T_{i}\right)-\Delta H_{s}}\right] \frac{\left(r_{b}+G_{a} / \rho_{s}\right)}{\exp \left[C_{p} \delta_{o}\left(\rho_{s} r_{b}+G_{a}\right) / k\right]-1}
$$

The base combustion zone thickness $\delta_{o}$ can be estimated from

$$
\delta_{o}=\frac{k}{\rho_{s} r_{o} C_{p}} \cdot \ln \left[1+\frac{C_{p}\left(T_{F}-T_{s}\right)}{C_{s}\left(T_{s}-T_{i}\right)-\Delta H_{s}}\right]
$$

where $r_{o}$ is the base burning rate resulting from pressure dependent and erosive burning effects. For a given propellant, the burning rate augmentation is related to increasing $a_{n}$ as show in Fig. 2.4 [1]. The accelerative mass flux $G_{a}$ is determined by $a_{n}$ and the corresponding reduction of that augmentation comes through lateral or longitudinal acceleration, moving the resultant acceleration vector away from the reference orientation angle of zero (perpendicular to surface) to some finite value [6] determined from

$$
G_{a}=\left\{\frac{a_{n} p}{r_{b}} \frac{\delta_{o}}{R T_{f}} \frac{r_{o}}{r_{b}}\right\}_{\phi=0^{\circ}} \cos ^{2} \phi_{d}
$$

The displacement orientation angle $\phi_{d}$ is a function of $\phi$, reflecting the increased reduction in augmentation that one observes experimentally as $\phi$ increases can be calculated as

$$
\phi_{d}=\tan ^{-1}\left[K\left(\frac{r_{o}}{r_{b}}\right)^{3} \tan \phi\right]
$$

where correction factor $K$ has been experimentally determined to be approximately 
Figure 2.4: Burning rate augmentation of AP/PBAA solid propellant as a function of normal acceleration at two different pressures

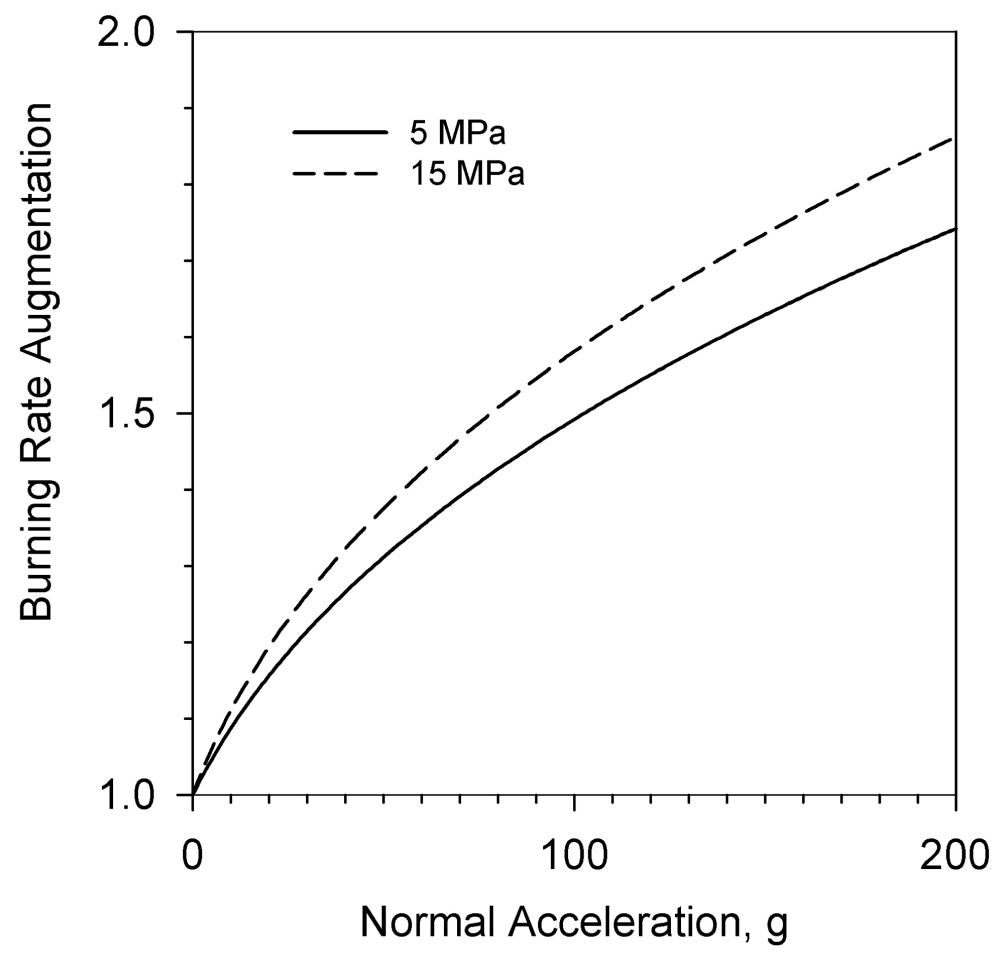

8 [1] and $\phi$ as shown in Fig. 3.3 is calculated as

$$
\phi=\tan ^{-1}\left(\frac{a_{l}}{a_{n}}\right)
$$

where $a_{l}$ and $a_{n}$ are the longitudinal and normal accelerations. The predicted effect of decreasing burning rate augmentation due to normal acceleration as orientation angle $\phi$ increases due to increasing longitudinal acceleration $a_{l}$ is shown in Fig. 2.5 $[1,6]$. 
Figure 2.5: Burning rate augmentation of AP/PBAA solid propellant as function of resultant acceleration angle, at two different $a_{n}$ levels (at $5 \mathrm{MPa}$ pressure).

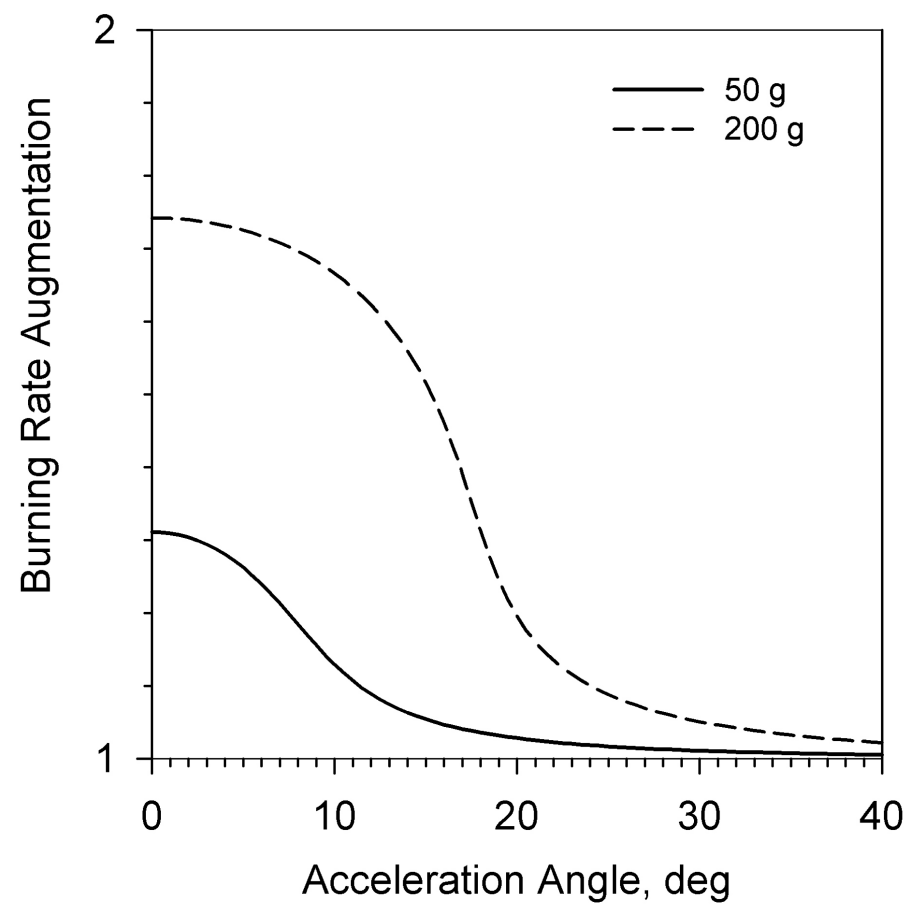

In practice, in a free flight situation, the rocket vehicle (and the motor within) will likely be undergoing significant forward longitudinal acceleration with the application of additional thrust at some point in a flight mission. This forward acceleration of the vehicle is the effective $a_{l}$ acting to potentially reduce the effect of spin-induced normal acceleration on the solid propellant's burning process, as per Eq. 2.17. From reference [9], presented as an earlier part of this thesis study, an example of this influence is shown in Fig. 2.7, with a constant $a_{l}$ of $15 \mathrm{~g}$ being applied during the spin period. Comparing the baseline case of Fig. 2.6 and the 15 g case of Fig. 2.7, 
one can see a significant reduction in the spin-induced chamber pressure buildup. The result is consistent with a mean acceleration orientation angle of around $10^{\circ}$ (see Fig. 2.5). The corresponding sea-level thrust-time profile under a $15 \mathrm{~g}$ forward acceleration is provided in Fig. 2.8.

Figure 2.6: Head-end pressure-time profiles of AP/PBAA solid rocket motor, baseline case, and manoeuvring case with $20 \mathrm{rps}$ spin, $3 \mathrm{~s}<\mathrm{t}<4.5 \mathrm{~s}$, and zero longitudinal acceleration

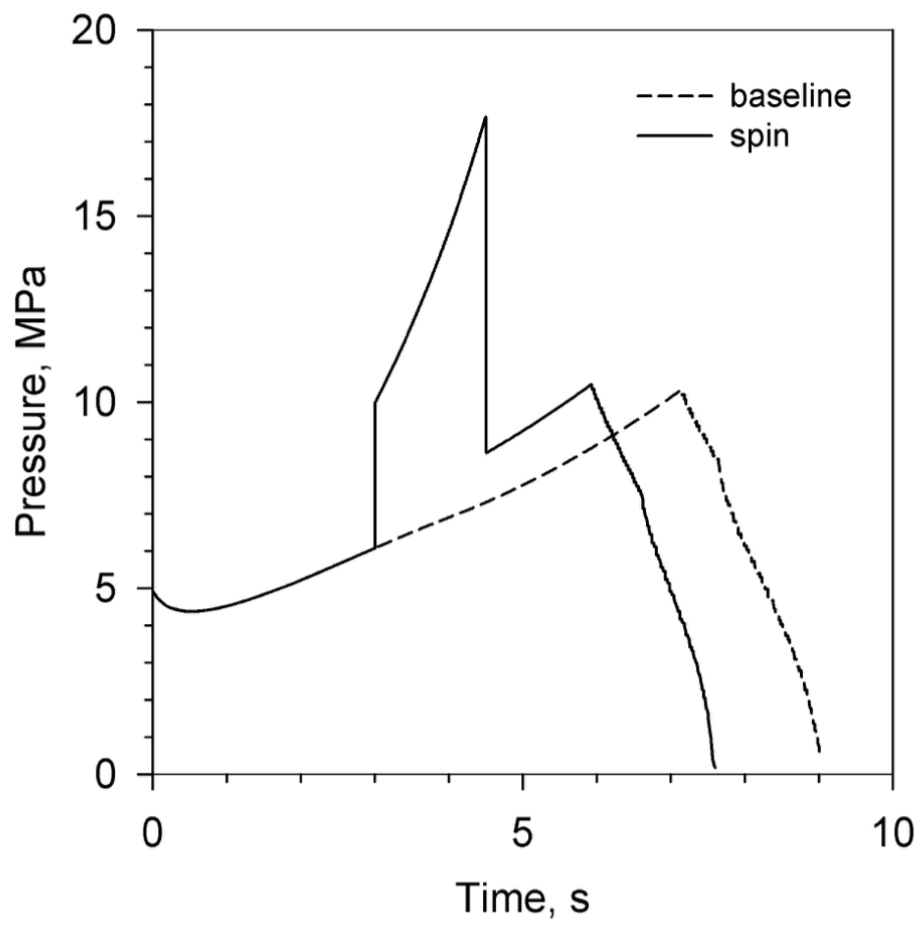


Figure 2.7: Head-end pressure-time profiles of AP/PBAA solid rocket motor, baseline case, and manoeuvring case with $20 \mathrm{rps}$ spin, $3 \mathrm{~s}<\mathrm{t}<4.5 \mathrm{~s}$, and $15 \mathrm{~g}$ longitudinal acceleration

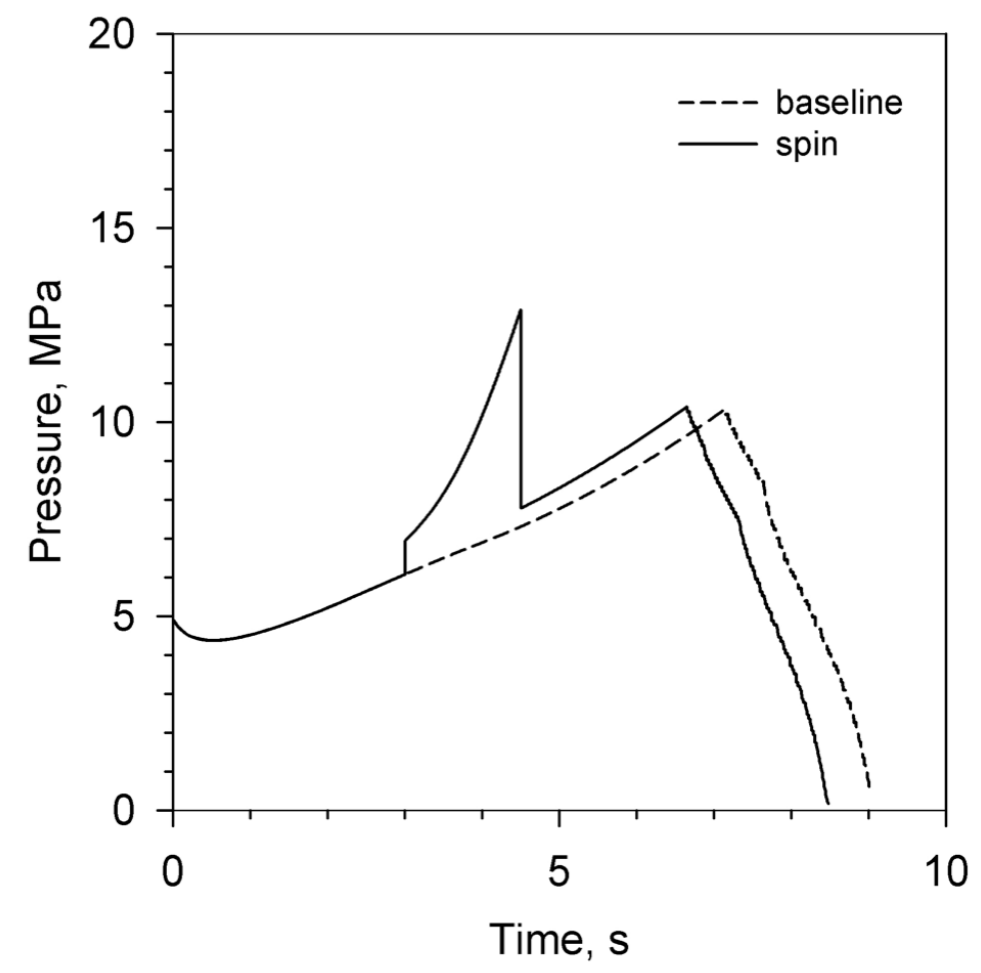


Figure 2.8: Sea-level thrust-time profiles of AP/PBAA solid rocket motor, baseline case, and manoeuvring case with 20 rps spin, $3 \mathrm{~s}<\mathrm{t}<4.5 \mathrm{~s}$, and $15 \mathrm{~g}$ longitudinal acceleration

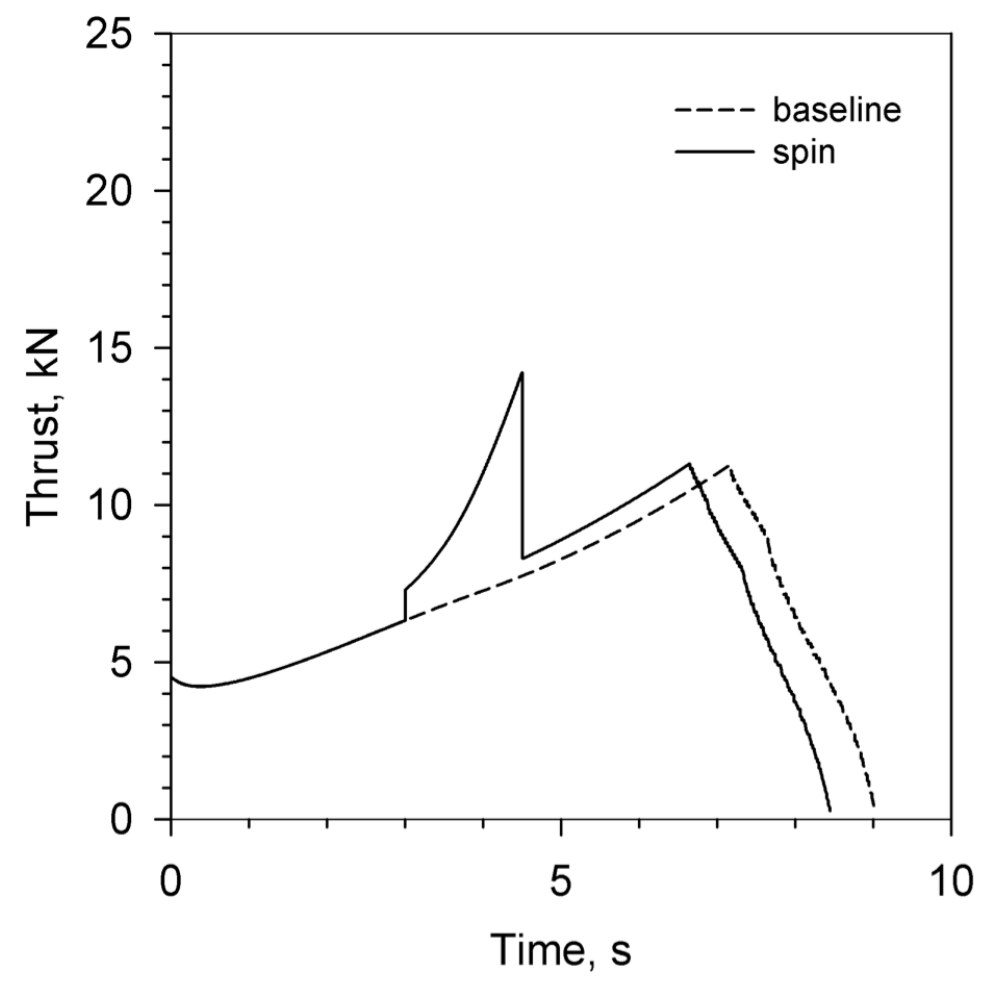




\section{Thrust Modulation of Solid Rocket Motors}

As already presented, there are a number of mechanisms governing the solid propellant burn rate. By dynamically adjusting one of these mechanisms, the thrust of the SRM may be adjusted over the baseline thrust profile. Historically, methods to increase the chamber pressure have been used, but these methods only increase the thrust modestly at the expense of very high chamber pressures and momentum losses due to obstructions in the gas flow. An alternative strategy, employing normal acceleration to vary the thrust produced by the motor, will be described in this section. A comparison of this novel approach will be made with the conventional approach of using a pintle (i.e. variable throat area) nozzle.

\subsection{Burning Rate Augmentation Due to Increased Chamber Pressure}

To modulate the thrust being delivered from an SRM, one or more of the burning rate mechanisms would have to be dynamically modified during the operation of the motor. For pressure-dependent burning, this is commonly done by varying the throat area of the convergent-divergent nozzle using a moveable plug called a pintle 
as shown in Fig. 3.1 [10]. Moving the pintle towards the nozzle throat reduces the cross-sectional area of the throat. The pintle is operated hydraulically, pneumatically, or electrically as commanded by the flight control system.

Figure 3.1: Moveable pintle varying the throat area of the nozzle
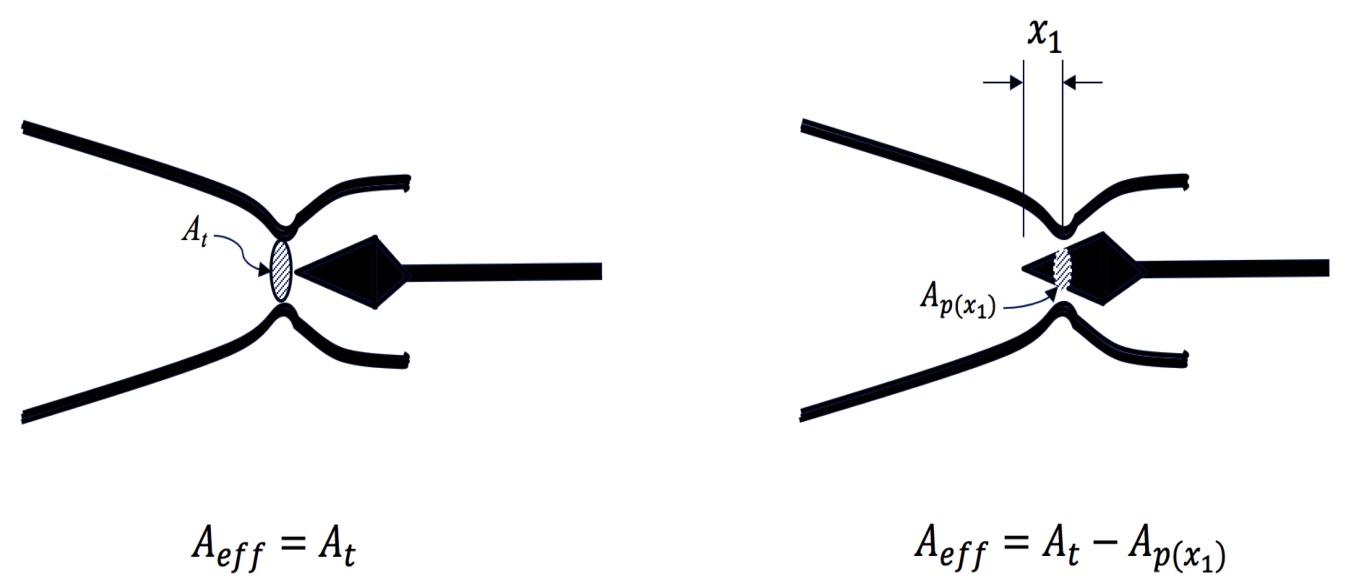

The effective area of the nozzle throat $A_{\text {eff }}$ is found by subtracting the area of the pintle at a particular extended position $x_{1}$ from the base area of the throat when the pintle is fully retracted. From Eq. 2.2, by reducing the cross-sectional area of the nozzle throat, the chamber pressure will be increased. This increased chamber pressure will increase the propellant burning rate via Eq. 2.6 and from Eq. 2.3, increasing the propellant burning rate will increase the mass flow which therefore via Eq. 2.1 increases the thrust. From Heo [10] it was observed that in many of the studies that complicated shock waves and flow separation in the pintle nozzle occurred around the nozzle and that these induced interference phenomena, turbulence, and flow instability. 


\subsection{Burning Rate Augmentation Due to Normal Acceleration}

The propellant burning rate can be influenced by establishing a normal acceleration

field to the burning surface. This can be done by spinning the rocket on its longitudinal axis as shown in Fig. 3.2. In 1965, Bastress [11] developed a theoretical model that predicted that the burn rate augmentation experienced in a spinning SRM was due to an effective reduction in throat area as a result of the tangential velocity imparted to the central gas flow. A later experimental study by Broddner [16] in 1970 compared a spinning rocket engine with a conventional single central nozzle and one with multiple peripheral nozzles (to cancel out the effective throat reduction effect due to spin-induced vortex flow). It was concluded that in the latter case a burning rate increase was noted due to the normal acceleration effects alone. It should be noted that in the Broddner experiments, very high rotational velocities were used to establish the spin-induced nozzle-area reductions and normal accelerations to the propellant burning surface, in excess of 11,000 rpm (over 180 rotations per second). 
Figure 3.2: SRM spinning as a means of inducing a normal acceleration field

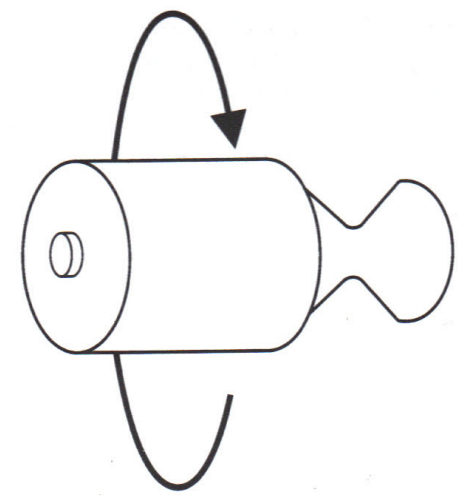

Figure 3.3: Schematic diagram of acceleration vectors acting near the propellant surface

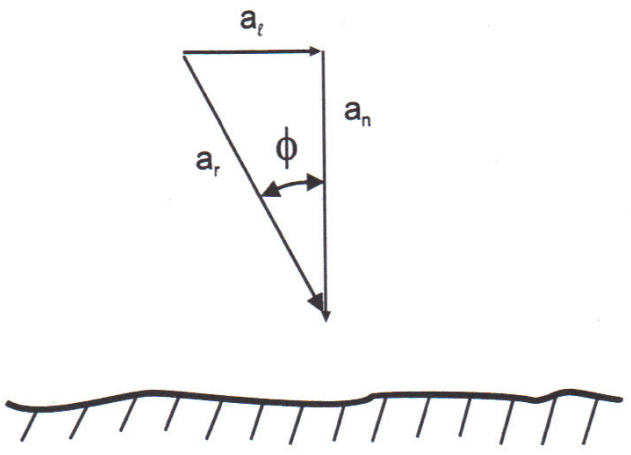

\subsection{Acceleration Effects in Metallized and Non-Metallized Propellants}

With regards to the effect of a normal acceleration field on metallized and nonaluminized propellants as discussed by Glick [12], Northam [18], Crowe [19] and Fuchs [20], it was hypothesized that metallized propellants (that is, propellants that contain a quantity of metal particles as fuel or as combustion modifiers) should respond differently to a normal acceleration field than non-metallized ones. For metallized propellants, the studies theorized that this would be due to the metal particles being held closer to the propellant burning surface for a (relatively) longer period of time due to the normal acceleration, and that this results in an increased heat transfer to the fuel grain which increases the burning rate. For non-metallized propellants, the same study suggested that there was little burning rate response 
to acceleration fields under $100 \mathrm{~g}$ and using a granular diffusion flame model, the burning rate increase is predicted to be due to the effect of the acceleration field on the heterogeneous structure of the gas phase reaction zone.

These early efforts were not consistent with the emperical results of the time (e.g. some high-percentage metallized propellants saw less burning-rate augmentation than lower percentage propellants [20]) and relied on experimentally determined coefficients [4] which made it difficult to generalize the analytical models for broader

engineering applications. Greatrix $[1,4,9]$ took a different approach to modelling the physics underlying the phenomenon. In this later work, it was suggested that the effect of spinning on the rate of combustion was due to a compressed combustion zone (reduced flame height) under a normal acceleration field and that this was the dominant effect for the burning rate augmentation seen in spinning solid rocket motors. This model agrees well with experimental data $[4,6]$ for non-metallized fuels and reasonably well for a number of metallized fuels for different metal particle loading conditions. It is important to know that the Greatrix model concurs with experimental observations, in that a higher augmentation is likely to be seen with lower base burning rate propellants.

\subsection{Effects of Orientation Angle on Acceleration Effects}

The Glick, Northam and Greatrix studies also highlighted the idea that the burn rate augmentation effect is dependent on the orientation angle that results from 
the combination of the normal acceleration $a_{n}$ and any longitudinal acceleration $a_{l}$ affecting the SRM at the same time. Increasing values of the total longitudinal acceleration displacement angle decrease the accelerative mass flux and therefore the burning rate augmentation. Investigations by King [22] and Langhenry [23] suggested that the peak augmentation ratio might be governed by a simple cosine relationship

$$
\frac{r_{b}}{r_{o}}=\left.\frac{r_{b}}{r_{o}}\right|_{\phi=0} \cos \phi
$$

but it was noted by Langhenry that a much stronger reduction was occurring. Greatrix [6] surmised that the longitudinal acceleration field may create a more significant effect on the liquid-phase molecules than for the gas molecules further up the combustion zone suggesting a corrected peak accelerative mass flux as shown in Eqs. 2.16 and 2.17 noting that the burning rate augmentation due to the normal acceleration decreases dramatically when the $\phi$ angle (as shown in Fig. 3.3) is greater than $10^{\circ}[6,9]$.

It is suggested in this thesis that increasing the normal acceleration field by spinning the SRM faster may at least partially overcome the decreased burn rate augmentation due to longitudinal acceleration experienced by the SRM in flight. 


\section{Internal Ballistic Modelling and Analysis}

Internal ballistics deals with the combustion of the propellant and internal flow within the motor. For a solid rocket motor firing, one may need to solve the conservation equations of mass, linear momentum and energy for both the particle and gas phases of the internal flow.

\subsection{Equations of Motion}

\subsubsection{Gas Phase}

For a quasi-steady state operation (no analysis of more rapid transients), the following are the one-dimensional equations for conservation of mass, momentum and energy of the core gas at a given time moving left to right from the head end of the SRM towards the nozzle [1]:

$$
\begin{gathered}
\frac{\mathrm{d}(\rho u)}{\mathrm{d} x}=-\frac{1}{A} \frac{\mathrm{d} A}{\mathrm{~d} x} \rho u+\left(1-\alpha_{p}\right) \rho_{s} \frac{4 r_{b}}{d}-\left(\frac{4 r_{b}}{d}\right) \rho \\
\frac{\mathrm{d}}{\mathrm{d} x}\left(\rho u^{2}+p\right)=-\frac{1}{A} \frac{\mathrm{d} A}{\mathrm{~d} x} \rho u^{2}-\left(\frac{4 r_{b}}{d}\right) \rho u-\rho a_{l}-\frac{\rho_{p}}{m_{p}} D
\end{gathered}
$$




$$
\begin{aligned}
\frac{\mathrm{d}}{\mathrm{d} x}(\rho u E+u p) & =-\frac{1}{A} \frac{\mathrm{d} A}{\mathrm{~d} x}(\rho u E+u p)-\left(\frac{4 r_{b}}{d}+\kappa\right) \rho E \\
& +\left(1-\alpha_{p}\right) \rho_{s} \frac{4 r_{b}}{d}\left(C_{p} T_{f}+\frac{v_{f}^{2}}{2}\right)-\rho u a_{l}-\frac{\rho_{p}}{m_{p}}\left(u_{p} D+Q\right)
\end{aligned}
$$

where $E=p /[(\gamma-1) \rho]+u^{2} / 2$ is the total specific energy of the gas at a given location, the drag force $D$ exerted on a particle of mean diameter $d_{m}$ is

$$
D=\frac{\pi d_{m}^{2}}{8} C_{d} \rho\left(u-u_{P}\right)\left|u-u_{p}\right|
$$

and $Q$ is the heat transfer from the gas to a given (spherical) particle is calculated by

$$
Q=\pi d_{m} k \cdot N u-\left(T-T_{p}\right)
$$

\subsubsection{Particle Phase}

For the particle phase, the corresponding conservation equations are:

$$
\begin{gathered}
\frac{\mathrm{d} \rho_{p} u_{p}}{\mathrm{~d} x}=-\frac{1}{A} \frac{\mathrm{d} A}{\mathrm{~d} x} \rho_{p} u_{p}+\alpha_{p} \rho_{s} \frac{4 r_{b}}{d}-\left(\frac{4 r_{b}}{d}\right) \rho_{p} \\
\frac{\mathrm{d} \rho_{p} u_{p}^{2}}{\mathrm{~d} x}=-\frac{1}{A} \frac{\mathrm{d} A}{\mathrm{~d} x} \rho_{p} u_{p}^{2}-\left(\frac{4 r_{b}}{d}\right) \rho_{p} u_{p}-\rho_{p} a_{l}+\frac{\rho_{p}}{m_{p}} D
\end{gathered}
$$




$$
\begin{aligned}
\frac{\mathrm{d} \rho_{p} u_{p} E_{p}}{\mathrm{~d} x} & =-\frac{1}{A} \frac{\mathrm{d} A}{\mathrm{~d} x}\left(\rho_{p} u_{p} E_{p}\right)-\left(\frac{4 r_{b}}{d}\right) \rho_{p} E_{p} \\
& +\alpha_{p} \rho_{s} \frac{4 r_{b}}{d}\left(C_{m} T_{f}+\frac{v_{f}^{2}}{2}\right)-\rho_{p} u_{p} a_{l}+\frac{\rho_{p}}{m_{p}}\left(u_{p} D+Q\right)
\end{aligned}
$$

\subsection{Computer Modelling of Internal Ballistics}

Using a variant of the QUROC numerical 1D finite-difference quasi-steady internal ballistics computer program employed at Ryerson University which solves the conservation equations for mass, momentum and energy of the internal flow of solid rocket motors, the chamber pressure of an SRM as a function of propellant burning surface area, etc., may be calculated under various conditions. From chamber pressure, the resulting thrust can be derived.

For this study, the QUROC program was modified to allow multiple changes to the nozzle diameter during the simulated firing to represent the presence of a pintle. This allowed the two thrust modulation techniques (chamber pressure induced burning rate augmentation, via pintle, and acceleration induced burn rate augmentation, via motor spin) to be compared.

\subsection{Reference Motor}

A summary of the reference motor parameters for the simulation runs are shown in Table 4.1. Note that the particle loading is considered small for this study's simulation runs, hence $\alpha_{p} \approx 0$. The solid propellant was chosen partly due to its 
lower base burning rate, which allows for a higher augmentation of $r_{b}$ for a given spin rate $\left(a_{n}\right.$ level $)[5,22]$.

The cylindrical propellant grain port geometry was chosen as it maximizes the augmentation of the burning rate due to normal acceleration versus non-cylindrical grain cross sections (such as star) as these introduce appreciable lateral acceleration components relative to the local propellant surface which result in a reduction in the burning rate augmentation effect [7]. 
Table 4.1: Summary of the reference solid rocket motor simulation parameters

\begin{tabular}{|c|c|}
\hline Parameter & Value \\
\hline Burning rate temperature sensitivity, $\sigma_{p}$ & $0.0016 \mathrm{~K}^{-1}$ \\
\hline Burning surface temperature, $T_{s}$ & $700 \mathrm{~K}$ \\
\hline Flame temperature, $T_{f}$ & $2300 \mathrm{~K}$ \\
\hline Grain diameter & $0.127 \mathrm{~m}$ \\
\hline Grain length & $1.47 \mathrm{~m}$ \\
\hline Initial grain port diameter & $0.035 \mathrm{~m}$ \\
\hline Initial propellant temperature, $T_{i}$ & $294 \mathrm{~K}$ \\
\hline Nominal nozzle throat diameter & $0.030 \mathrm{~m}$ \\
\hline Nozzle exit plane diameter & $0.070 \mathrm{~m}$ \\
\hline Particle mass loading fraction, $\alpha_{p}$ & 0 \\
\hline Propellant & $\mathrm{AP} / \mathrm{PBAA}$ \\
\hline Propellant density, $\rho_{p}$ & $1600 \mathrm{~kg} \mathrm{~m}^{-3}$ \\
\hline Propellant mass, $m_{p}$ & $27.5 \mathrm{~kg}$ \\
\hline Propellant pressure-dependent burning coefficient, $C$ & $0.000664 \mathrm{~m} \mathrm{~s}^{-1} \mathrm{kPa}^{-1}$ \\
\hline Propellant pressure-dependent burning exponent, $n$ & 0.25 \\
\hline Propellant specific heat (solid), $C_{s}$ & $1400 \mathrm{~J} \mathrm{~kg}^{-1} \mathrm{~K}^{-1}$ \\
\hline Ratio of specific heats, $\gamma$ & 1.24 \\
\hline Roughness height of propellant, $\epsilon$ & $200 \times 10^{-6} \mathrm{~m}$ \\
\hline Specific heat of gas, $C_{p}$ & $1953 \mathrm{~J} \mathrm{~kg}^{-1} \mathrm{~K}^{-1}$ \\
\hline Spin rate range & $10-22 \operatorname{rps}$ \\
\hline Variable throat diameter range & $76-100 \%$ \\
\hline
\end{tabular}




\section{Simulation Results}

\subsection{Reference Motor}

As a reference, a baseline was established by simulating the firing of the reference motor without any nozzle or spin implementations during the firing (note: the initial ignition and filling phase of the firing is not modelled by the code), the results of which are shown in Figures 5.1 and 5.2.

For the reference motor shown, the maximum chamber pressure was 10.09 $\mathrm{MPa}$ and the maximum thrust was $11.11 \mathrm{kN}$ which occurred just before burnout at 7.18 $\mathrm{s}$ into the firing after which there was a sharp decrease in chamber pressure and sea-level thrust as the last remnants of propellant are consumed and the chamber pressure reduced rapidly to local atmospheric pressure. 
Figure 5.1: Chamber pressure-time profile for reference motor firing

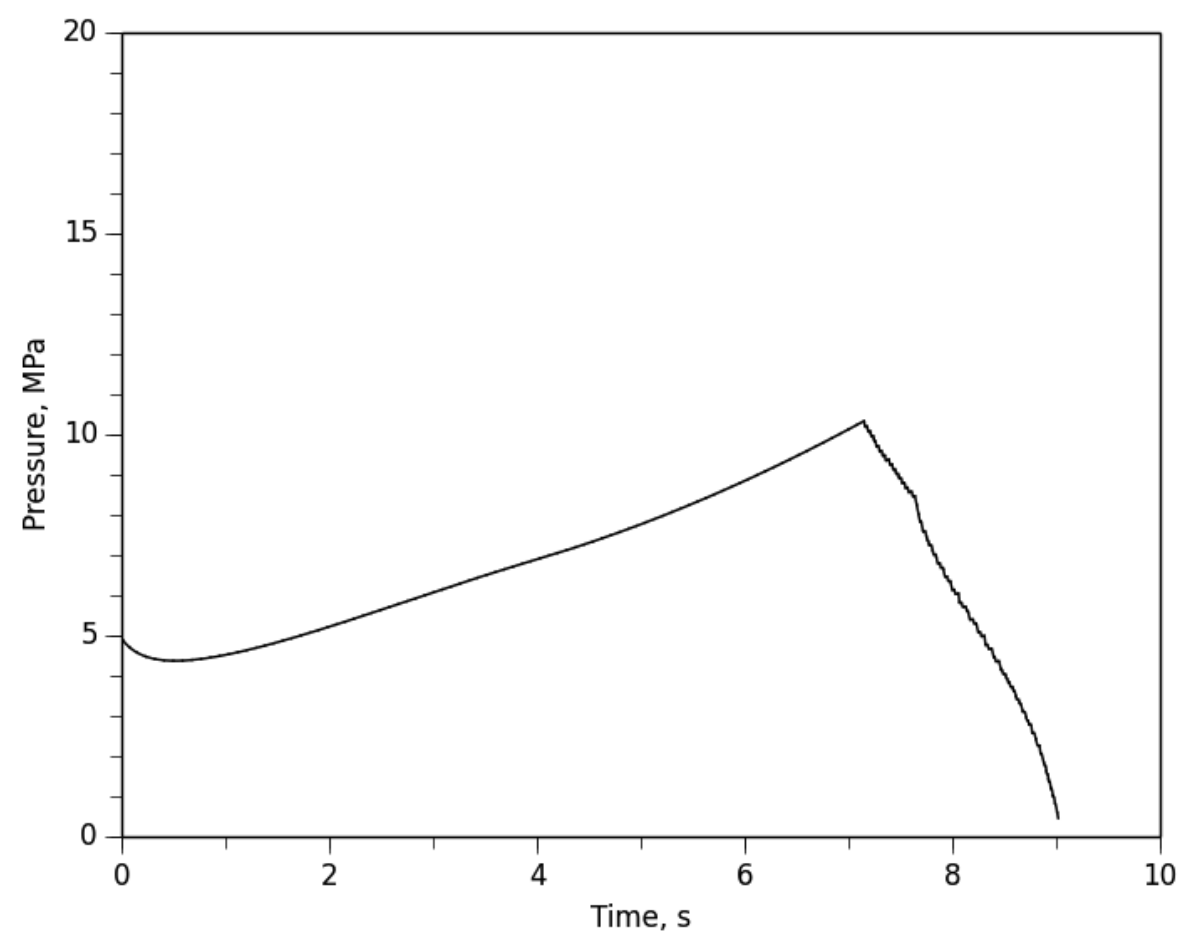


Figure 5.2: Sea-level thrust-time profile for reference motor firing

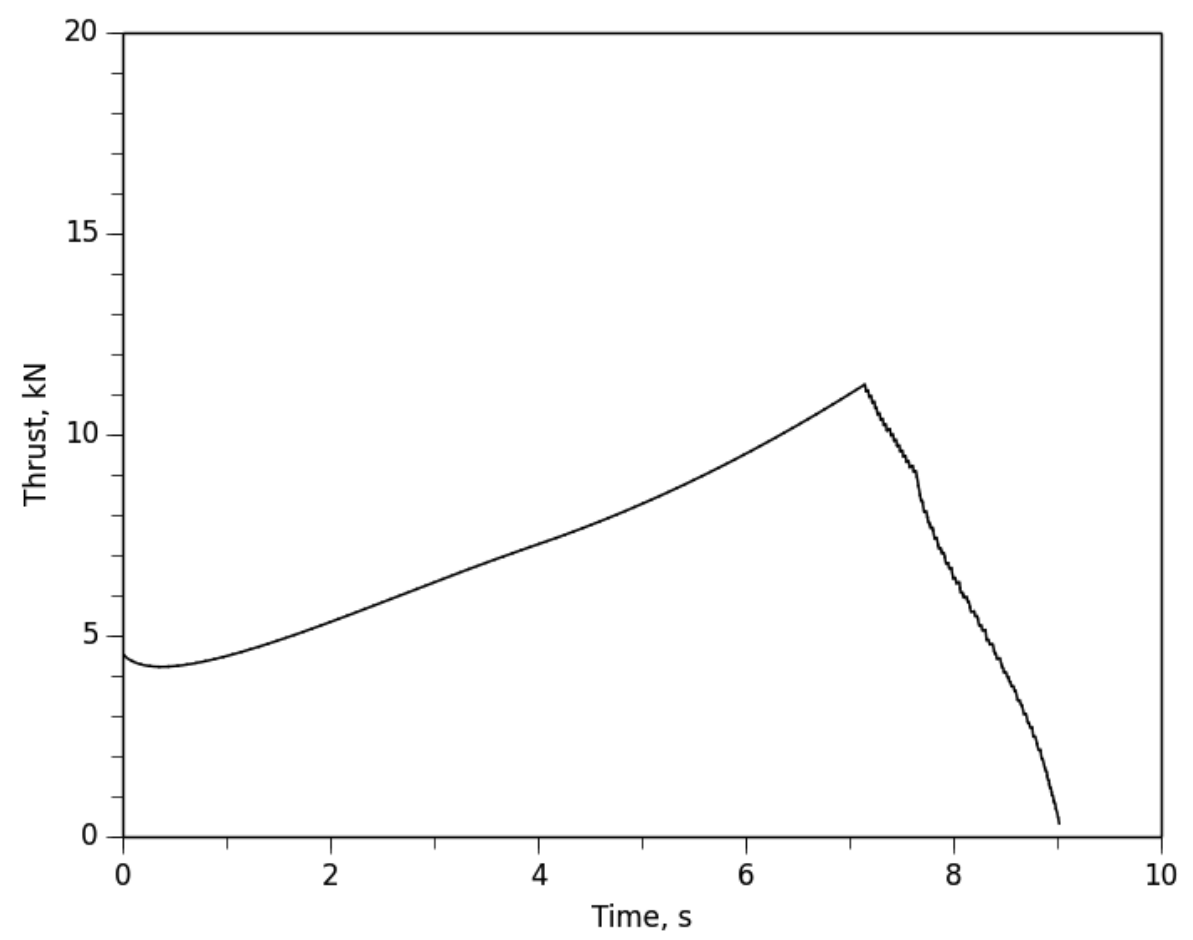




\subsection{Pintle Nozzle Motor}

The reference engine was again simulated but this time to simulate the use of a pintle, the nozzle throat diameter was reduced from $100 \%$ to $80 \%$ of the initial starting diameter of $0.030 \mathrm{~m}$ starting at 3.0 seconds into the firing. The throat diameter was further reduced at $3.75 \mathrm{~s}$ to $76 \%$. At $4.5 \mathrm{~s}$, the throat was opened up to $100 \%$ for the remainder of the simulated firing. The results of this simulation are shown in Figures 5.3 and 5.4 .

Figure 5.3: Chamber pressure profile for pintle motor firing, $80 \%$ throat dia., $3 \mathrm{~s}<\mathrm{t}<3.75 \mathrm{~s}, 76 \%$ throat dia. $3.75 \mathrm{~s}<\mathrm{t}<4.5 \mathrm{~s}$

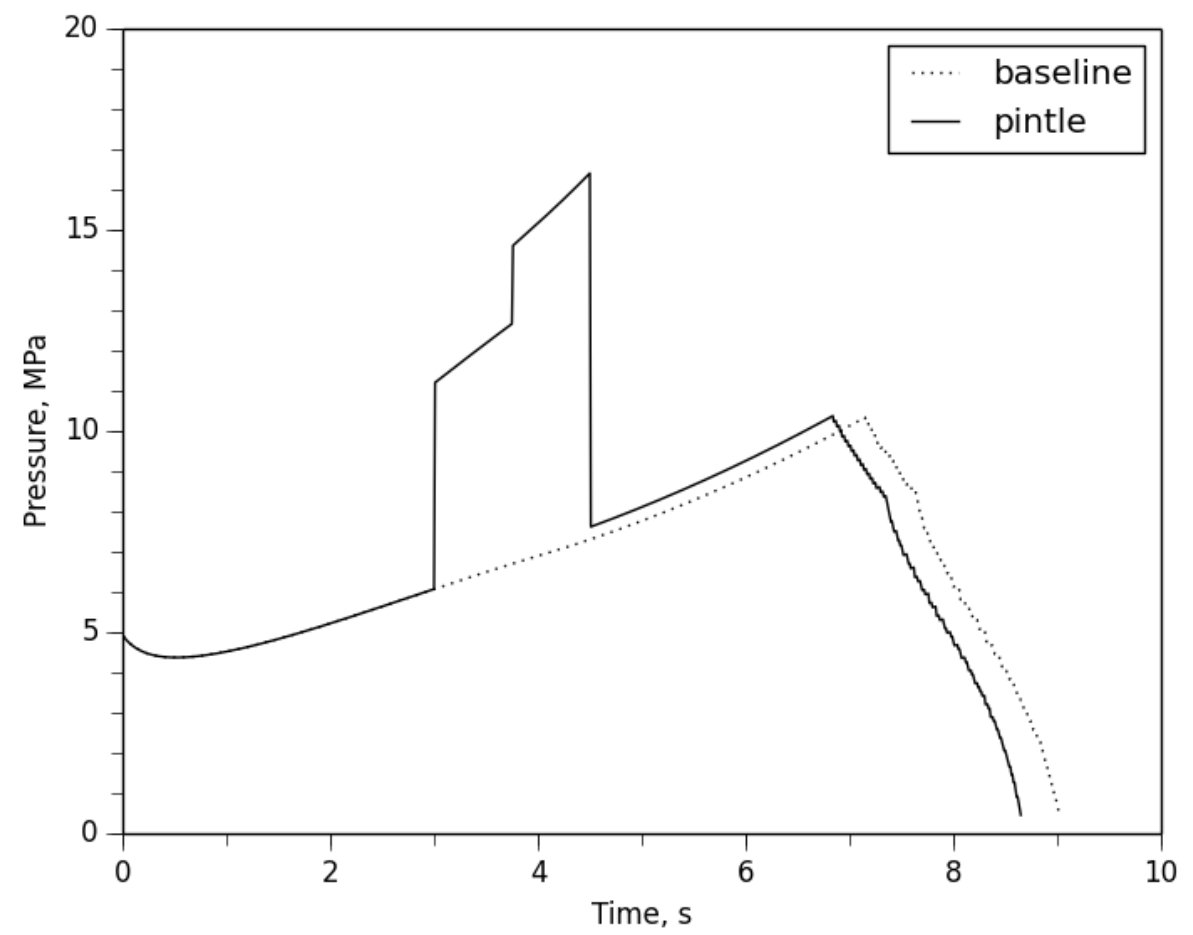


Figure 5.4: Thrust-time profile for pintle motor firing, $80 \%$ throat dia., $3 \mathrm{~s}<\mathrm{t}<3.75 \mathrm{~s}$, $76 \%$ throat dia. $3.75 \mathrm{~s}<\mathrm{t}<4.5 \mathrm{~s}$

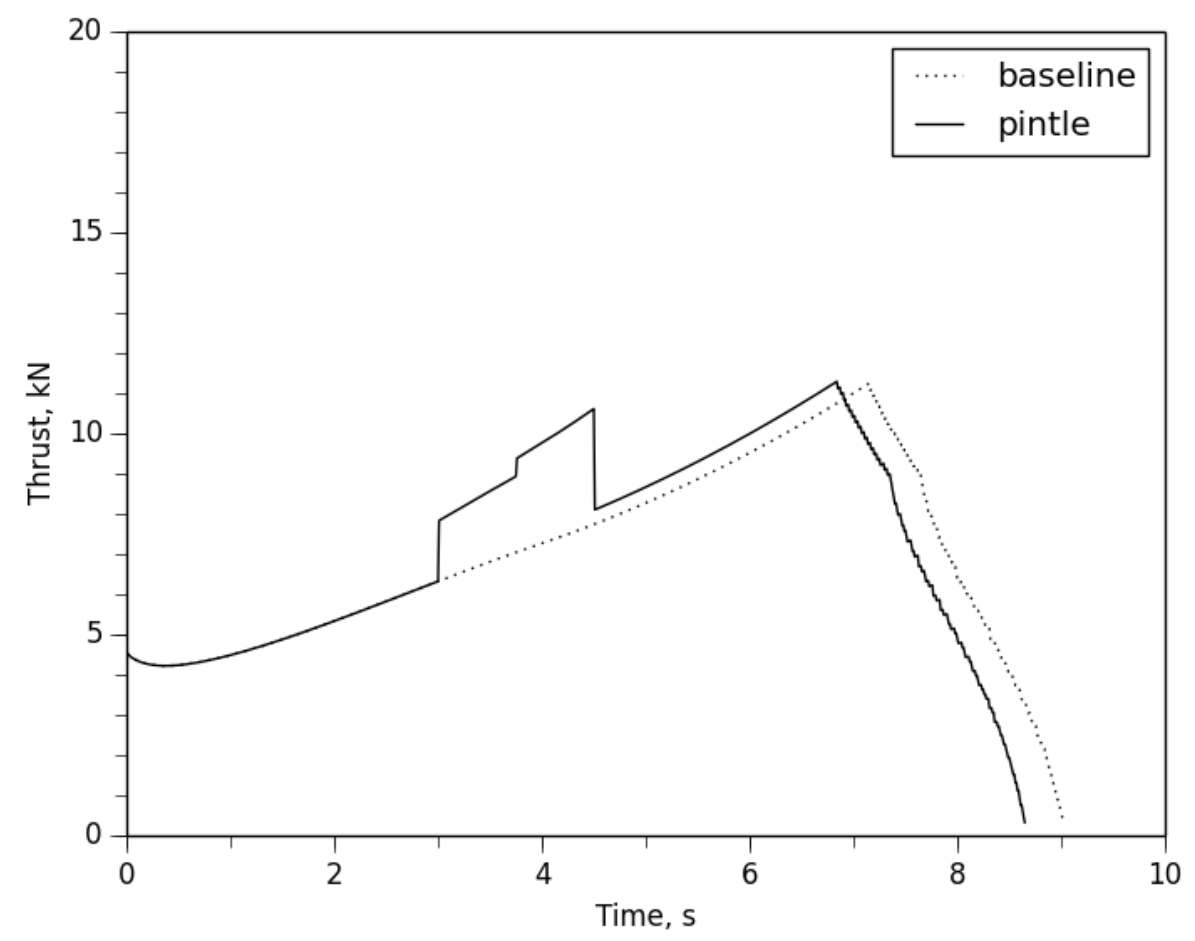

Note that because of the increased burning rate during the throat reduction period, the pintle motor does not burn as long as the reference motor. The maximum chamber pressure during the throat restriction period was 16.4 MPa and maximum thrust at the end of the period was $10.6 \mathrm{kN}$. The stepped throat diameter changes were arrived at by trial-and-error and were chosen to more closely approximate the resulting thrust curve of the spinning rocket motor simulation. 


\subsection{Spinning Rocket Motor}

For the spinning rocket motor, the reference motor was spun at 10 rps (600 rpm) starting at $3.0 \mathrm{~s}$ into the firing and lasting up to $4.5 \mathrm{~s}$ where the rotation was stopped and the motor continued to burn as normal to end of the propellant, with the resulting pressure and sea-level thrust profiles shown in Figures 5.5 and 5.6.

Figure 5.5: Chamber pressure-time profile for spinning motor firing, 10 rps, $3 \mathrm{~s}<\mathrm{t}<4.5 \mathrm{~s}$

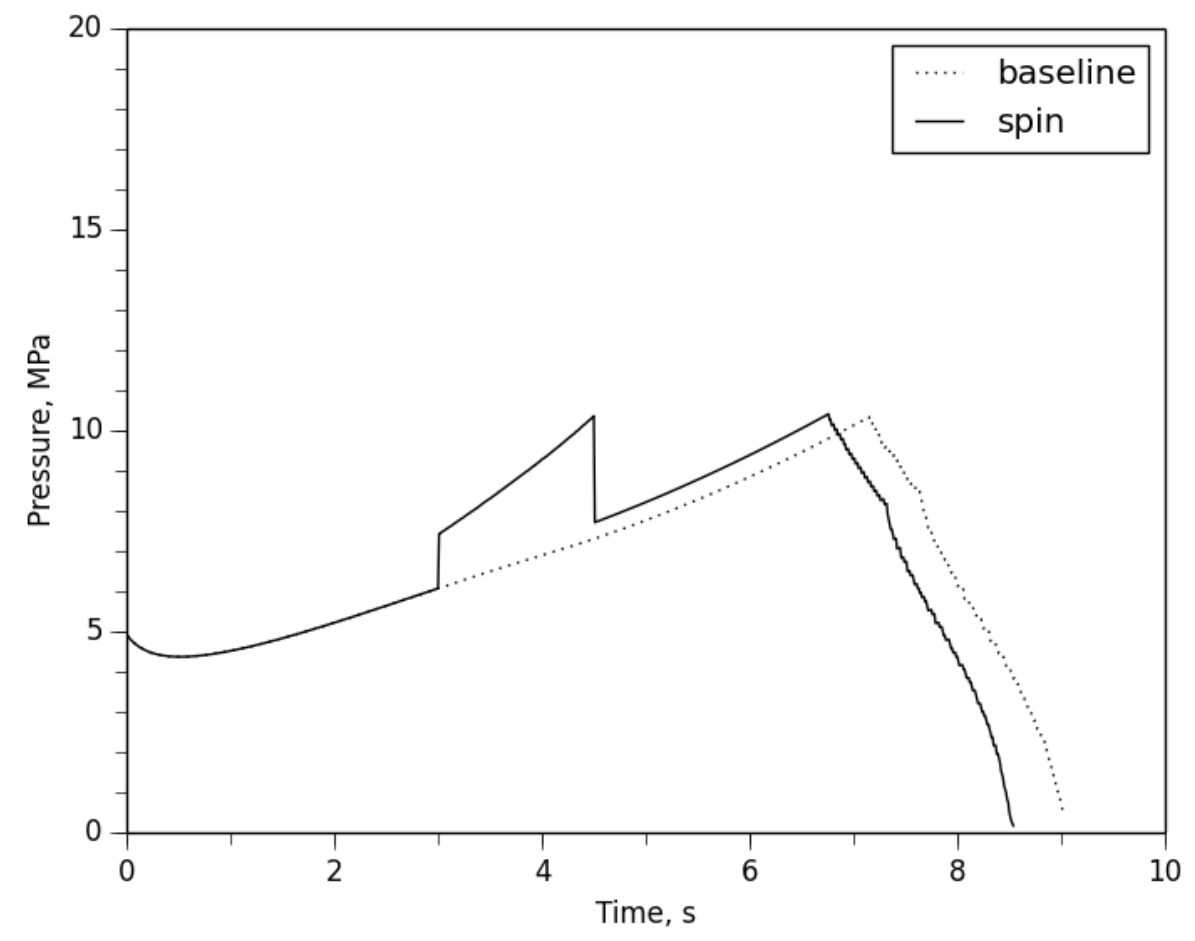

During the spinning period, the maximum chamber pressure was $10.4 \mathrm{MPa}$ and the maximum sea-level thrust was $11.3 \mathrm{kN}$ 
Figure 5.6: Sea-level thrust-time profile for spinning motor firing, $10 \mathrm{rps}, 3 \mathrm{~s}<\mathrm{t}<4.5 \mathrm{~s}$

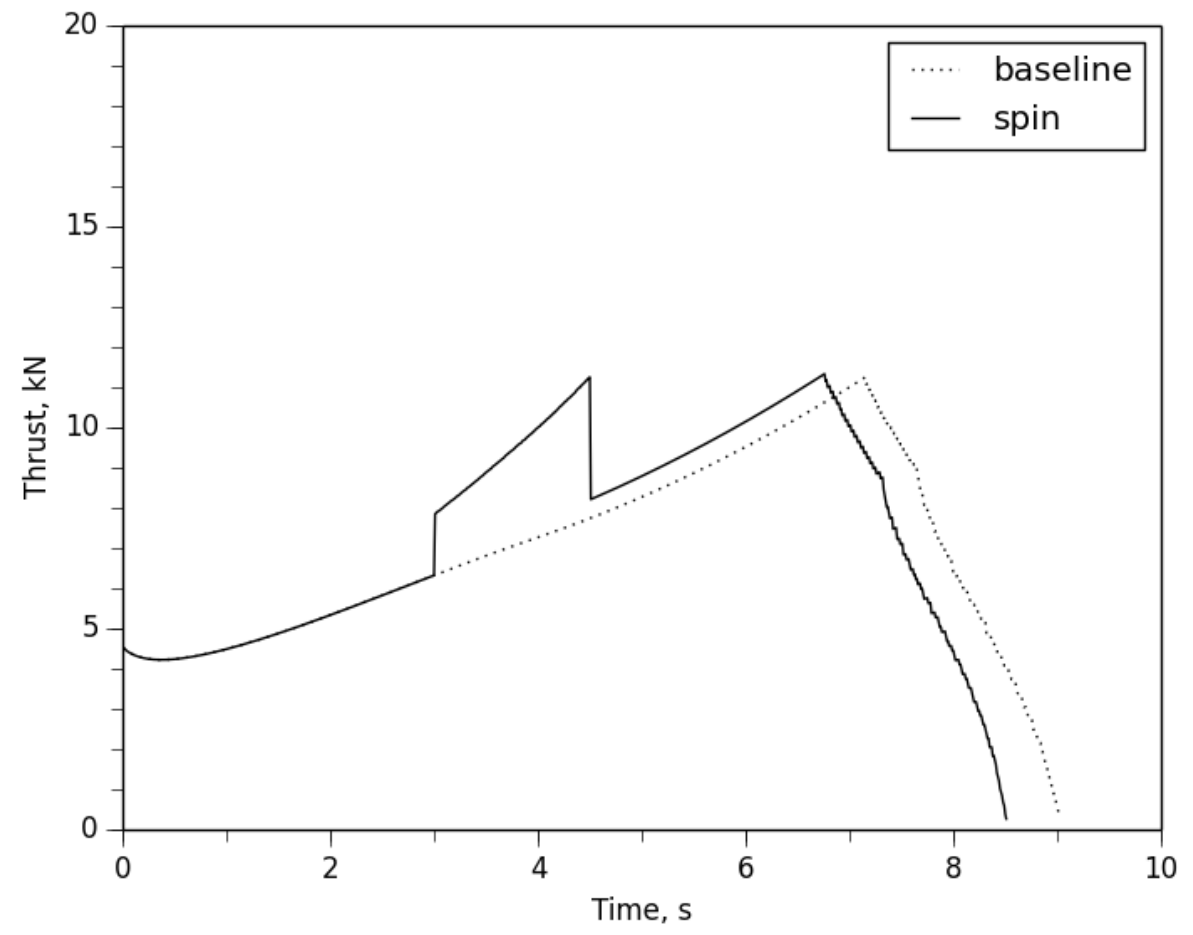

\subsection{Comparison of Pintle Nozzle and Spinning SRM}

Figures 5.7 and 5.8 overlay both the pintle and spinning SRM pressure and sea-level thrust profiles along with the baseline generated for the reference motor. 
Figure 5.7: Chamber pressure-time profiles for all motor firings

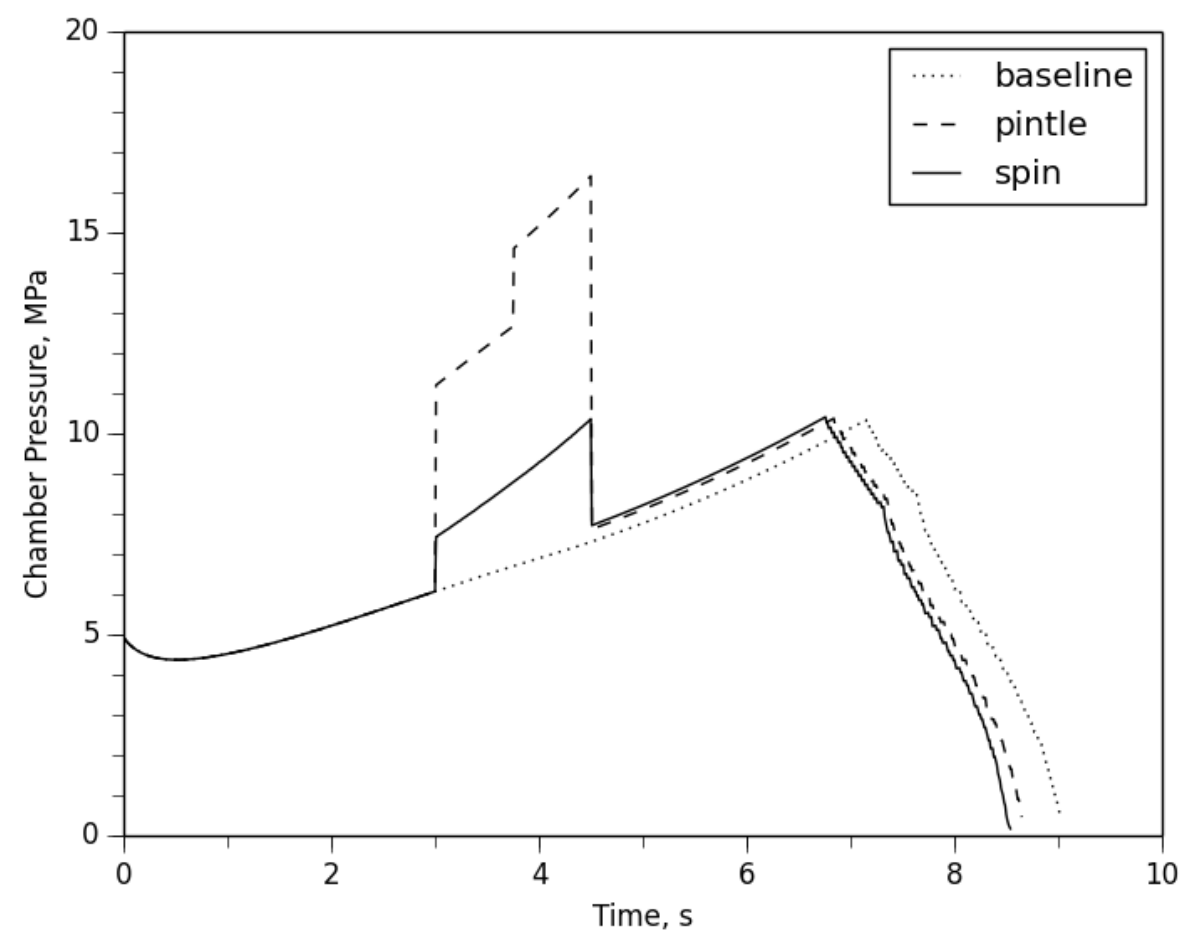


Figure 5.8: Sea-level thrust-time profiles for all motor firings

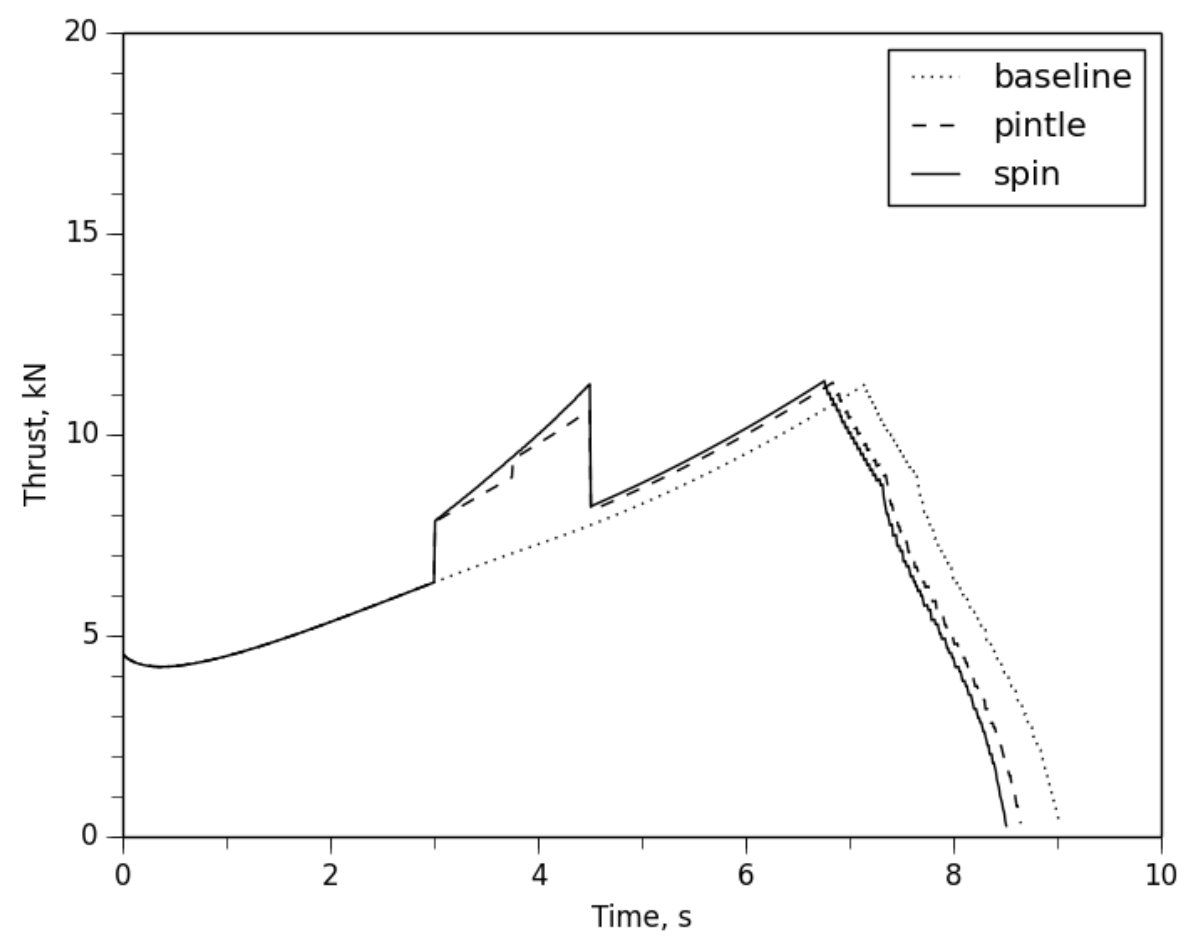




\subsection{Spinning Rocket at Maximum Chamber Pressure}

If one assumes for a moment that the maximum chamber pressure the reference rocket motor casing can withstand (due to material selection and thickness) is the maximum pressure generated by the pintle motor run (16.4 MPa), one can determine what the thrust generated at this pressure would be. Changing the spin rate of the motor from $10 \mathrm{rps}$ to $18 \mathrm{rps}$ (1080 rpm) generated the pressure and sea-level thrust profiles shown in Figures 5.9 and 5.10.

The maximum chamber pressure was $15.9 \mathrm{MPa}$ and the maximum sea-level thrust was $17.8 \mathrm{kN}$ during the spinning period. 
Figure 5.9: Sea-level chamber pressure-time profile for spinning rocket motor, 18 rps, $3 \mathrm{~s}<\mathrm{t}<4.5 \mathrm{~s}$

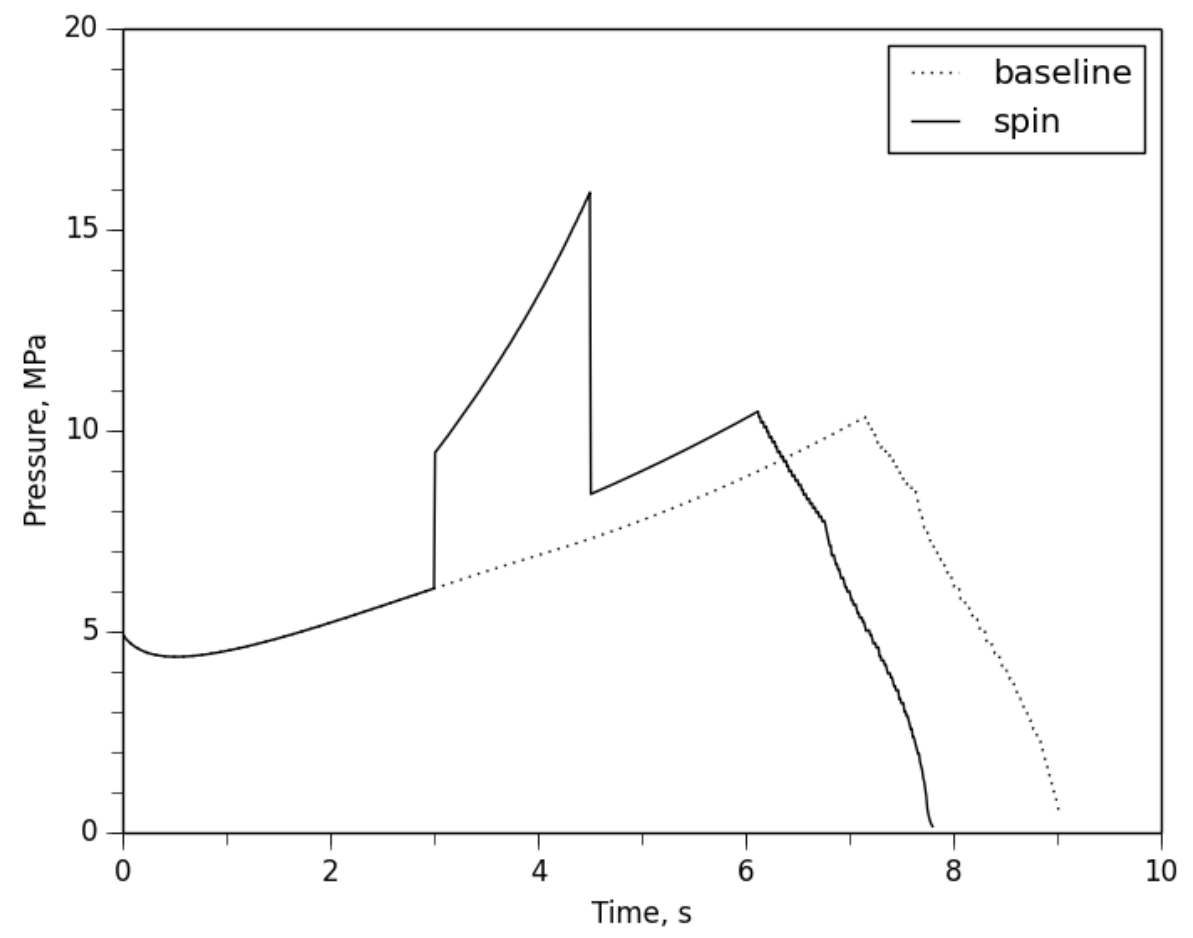


Figure 5.10: Sea-level thrust-time profile for spinning rocket motor, 18 rps, $3 \mathrm{~s}<\mathrm{t}<4.5 \mathrm{~s}$

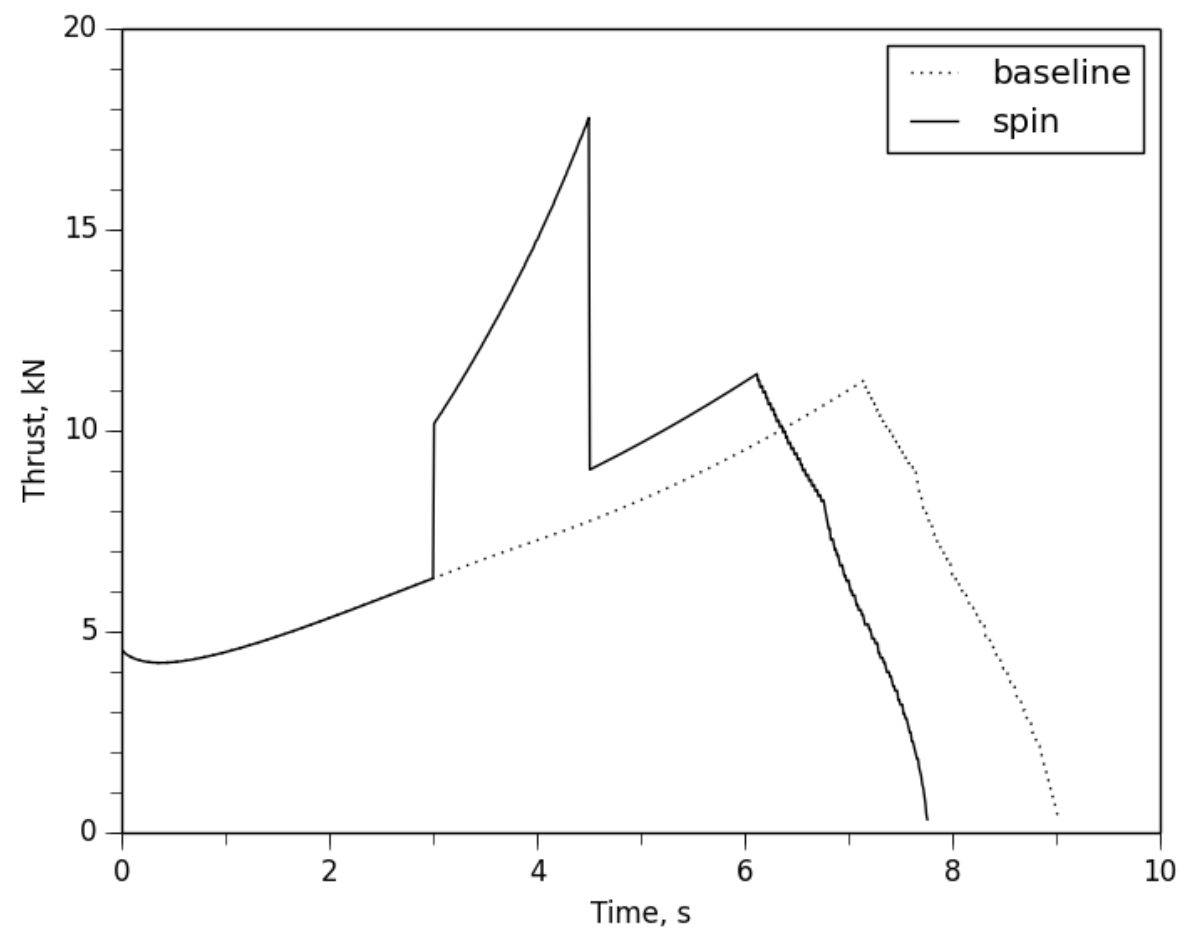




\subsection{Spinning Rocket With Longitudinal}

\section{Acceleration}

From Eq. 2.17 and 2.18, and Figure 2.5, it has been shown that the burning rate augmentation resulting from the normal acceleration generated due to spinning is attenuated by longitudinal acceleration which causes a resultant acceleration orientation angle in excess of $10^{\circ}$. The spinning rocket simulation was run again with a spin rate of $18 \mathrm{rps}$ as before but, in addition, a $15 \mathrm{~g}$ longitudinal acceleration was applied for the duration of the firing. Figs. 5.11 and 5.12 show the resulting chamber pressure-time and thrust-time profiles for this simulation. The maximum chamber pressure attained was $9.31 \mathrm{MPa}$ and the resulting maximum thrust was $10.04 \mathrm{kN}$.

To recover the thrust lost due to the longtitudinal acceleration, the spin rate of the SRM was increased from $18 \mathrm{rps}$ to $22 \mathrm{rps}(1320 \mathrm{rpm})$. Figs. 5.13 and 5.14 show the chamber pressure-time and thrust-time profiles for the reference solid rocket motor with a lateral acceleration of $15 \mathrm{~g}$ and spinning at $22 \mathrm{rps}$. During this simulation, the maximum chamber pressure attained was $16.76 \mathrm{MPa}$ and the maximum thrust generated was $18.78 \mathrm{kN}$.

Table 5.1 summarizes the chamber pressure and thrust increases recorded for each of the simulation runs. The Min/Max centripetal acceleration indicates the centripetal force based on the rate of spin for the particular simulation run at the minimum core diameter (when $a_{n}$ force would be at it lowest) and what it is calculated to be at burnout (maximum core diameter) if the SRM was still spinning at the same rate (when the $a_{n}$ force would be at its highest). 
Figure 5.11: Sea-level chamber pressure-time profile for a spinning rocket motor, $15 \mathrm{~g}$ longitudinal acceleration, $18 \mathrm{rps}, 3 \mathrm{~s}<\mathrm{t}<4.5 \mathrm{~s}$

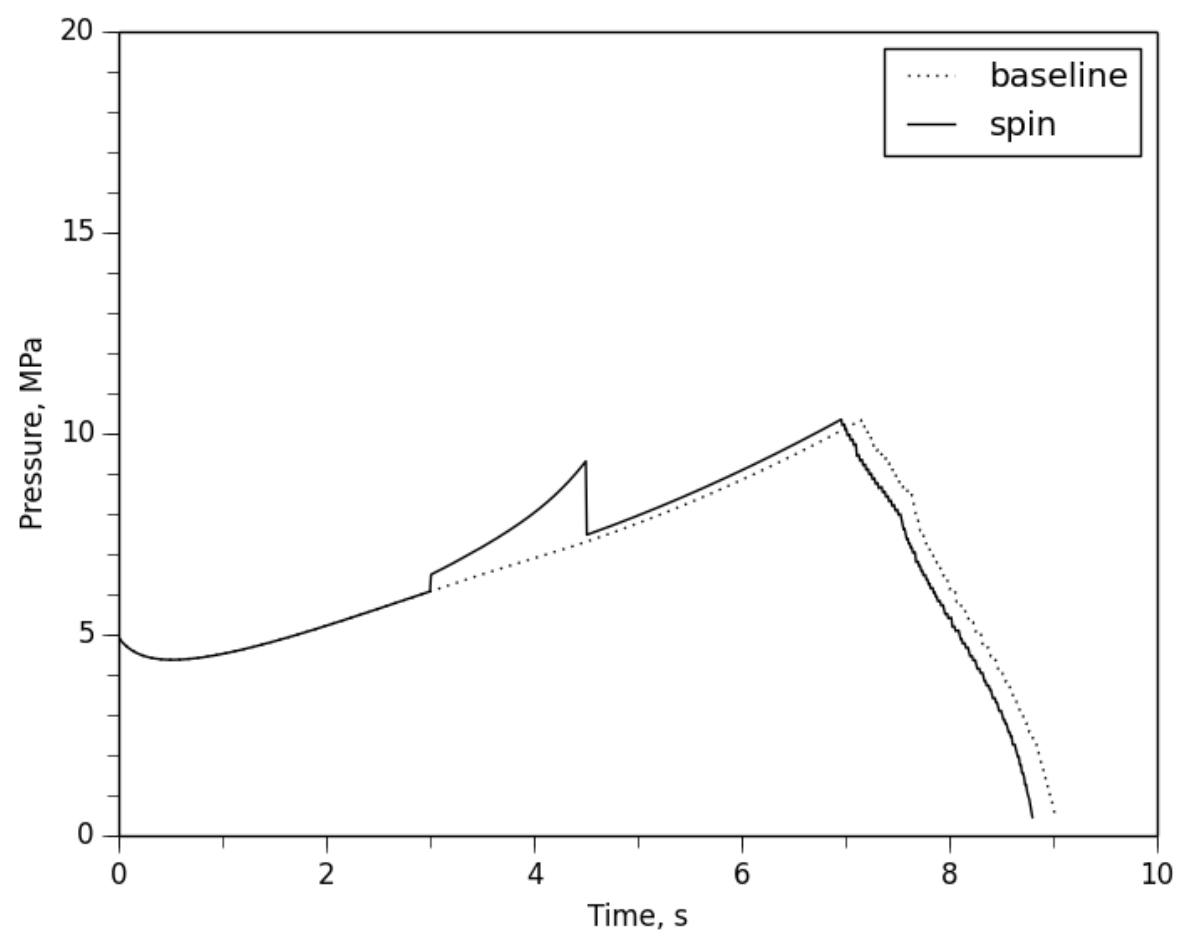

Table 5.1: Summary of the simulation results during the thrust augmentation period, 3 $\mathrm{s}<\mathrm{t}<4.5 \mathrm{~s}$

\begin{tabular}{lccc}
\hline Simulation Run & $\begin{array}{c}\text { Max. Chamber } \\
\text { Pressure, MPa }\end{array}$ & $\begin{array}{c}\text { Max. Thrust } \\
\mathrm{kN}\end{array}$ & $\begin{array}{c}\text { Centripetal Accel. } \\
\text { Min/Max, g }\end{array}$ \\
\hline Baseline & 10.1 & 11.1 & $\mathrm{n} / \mathrm{a}$ \\
Pintle & 16.4 & 10.6 & $\mathrm{n} / \mathrm{a}$ \\
Spin, 10 rps & 10.4 & 11.3 & $7 / 26$ \\
Spin, 18 rps & 15.9 & 17.8 & $23 / 83$ \\
Spin, 18 rps, 15 g long. accel. & 9.3 & 10.0 & $23 / 83$ \\
Spin, 22 rps, 15 g long. accel. & 16.7 & 18.8 & $34 / 124$ \\
\hline
\end{tabular}


Figure 5.12: Sea-level thrust-time profile for a spinning rocket motor, 15 g longitudinal acceleration, $18 \mathrm{rps}, 3 \mathrm{~s}<\mathrm{t}<4.5 \mathrm{~s}$

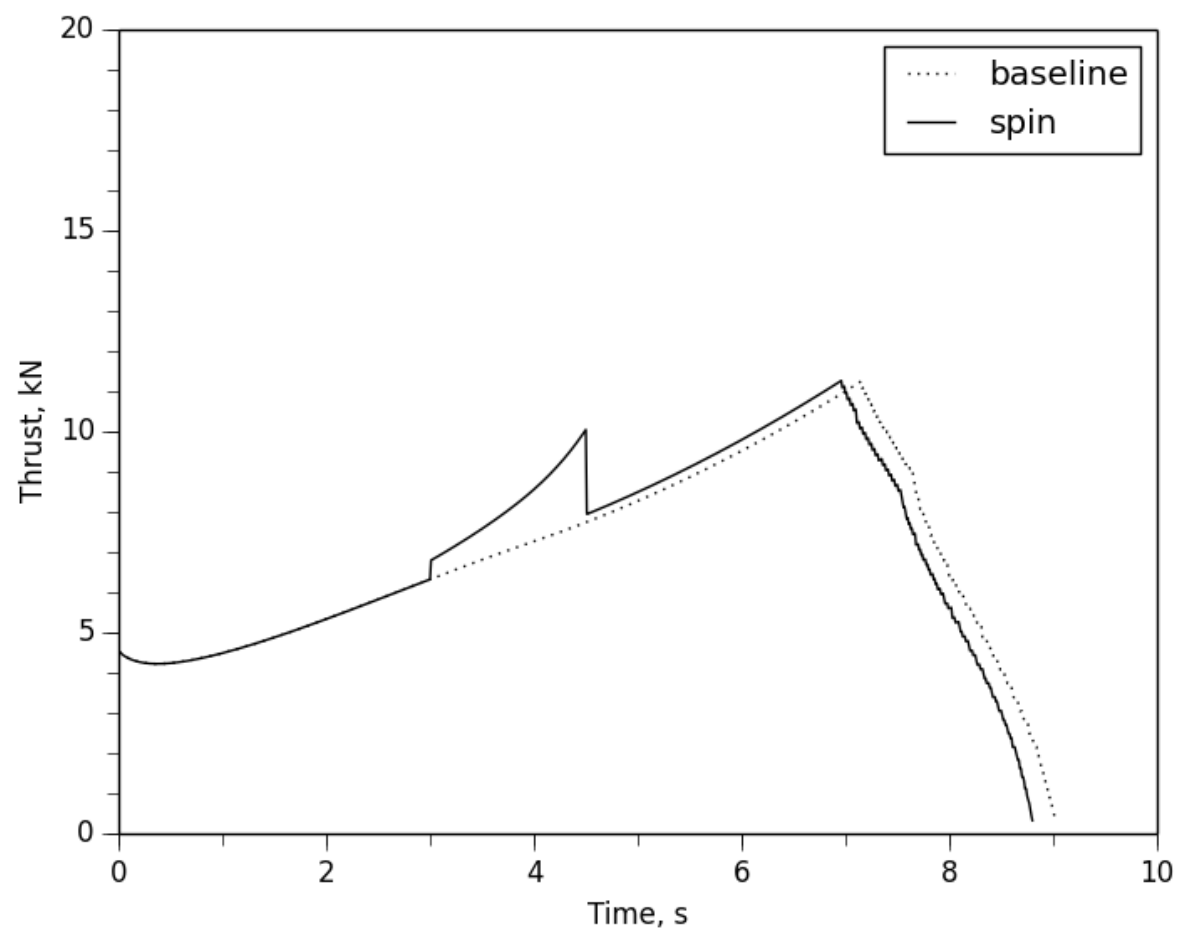


Figure 5.13: Sea-level chamber pressure-time profile for a spinning rocket motor, $15 \mathrm{~g}$ longitudinal acceleration, $22 \mathrm{rps}, 3 \mathrm{~s}<\mathrm{t}<4.5 \mathrm{~s}$

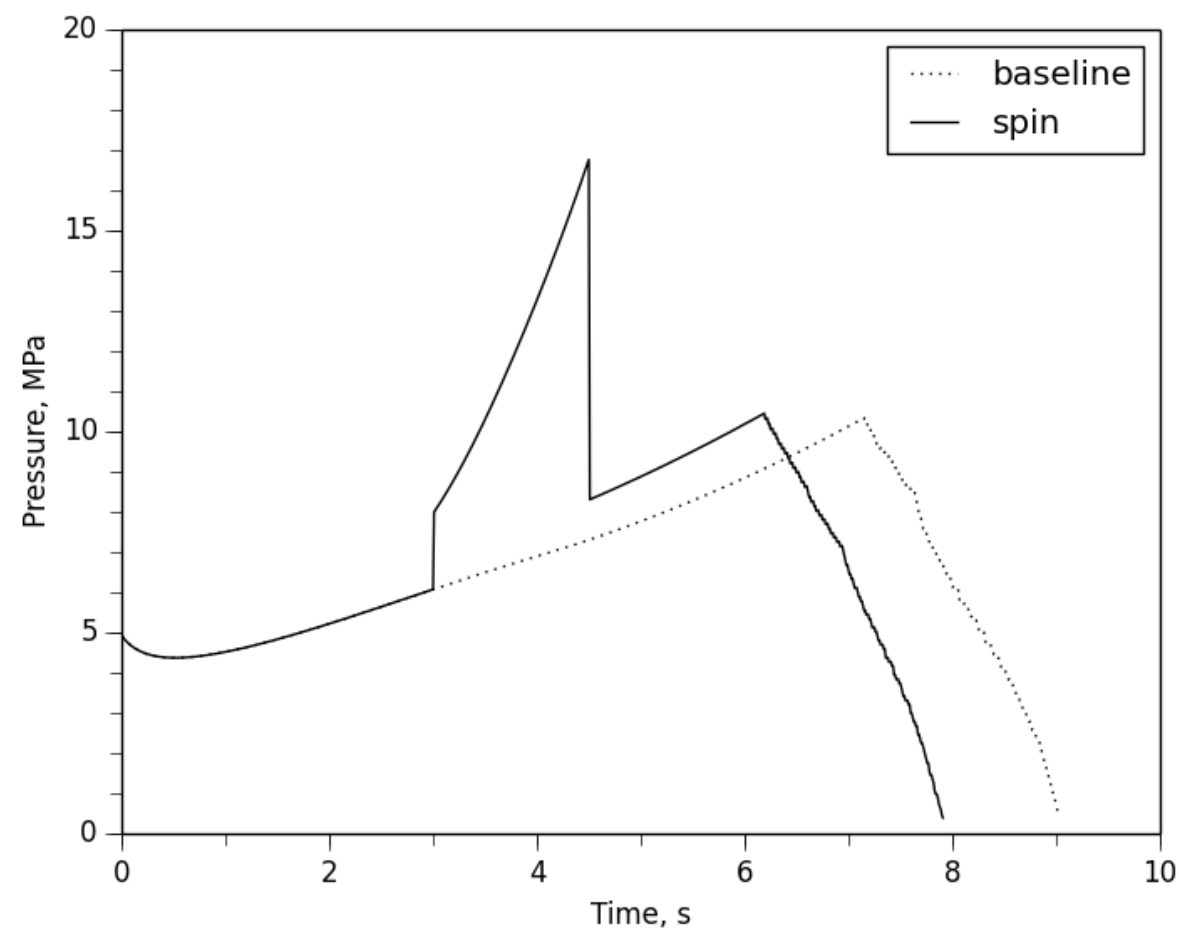


Figure 5.14: Sea-level thrust-time profile for a spinning rocket motor, $15 \mathrm{~g}$ longitudinal acceleration, $22 \mathrm{rps}, 3 \mathrm{~s}<\mathrm{t}<4.5 \mathrm{~s}$

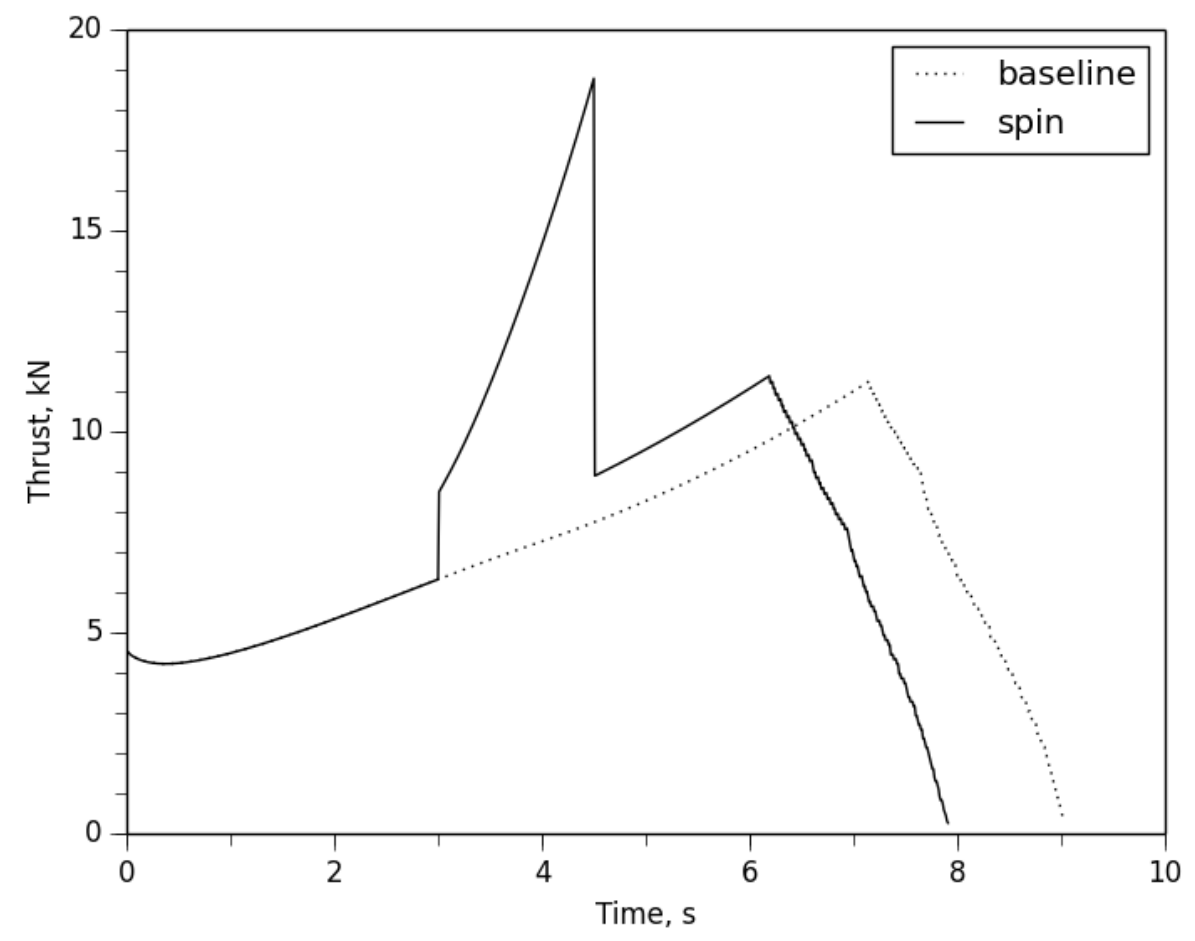




\section{Discussion of Results}

Comparing the pintle-based thrust augmentation technique to one relying on spinning, for the pintle-based rocket motor, the chamber pressure rose $124 \%$ over the baseline pressure at the same point in the burn while the sea-level thrust increased 37\% (Figs. 5.3, 5.4). With the spinning motor, the chamber pressure only rose $42 \%$

over the baseline pressure while the sea-level thrust increased $45 \%$ (Figs. 5.5, 5.6). The implication is that if we can achieve the same or better sea-level thrust increase via spinning than we can via the pintle design we could reduce the structural weight of the SRM casing without giving up performance.

More significant is the observation that assuming a maximum chamber pressure for the casing of $16.4 \mathrm{MPa}$, we can generate a $130 \%$ increase in the sea-level thrust $(17.8 \mathrm{kN}$ versus $7.7 \mathrm{kN}$, Figs. 5.9, 5.10) by spinning the SRM at a modest $18 \mathrm{rps}$ compared to the $37 \%$ increase available from the pintle design $(10.61 \mathrm{kN}$ versus 7.74 $\mathrm{kN}$, Figs. 5.3, 5.4). This result suggests that there is potentially a larger range of thrust profiles available to meet mission expectations when using the spinning approach versus a pintle-based design.

In the case where the spinning flight vehicle is undergoing a substantial longitudinal acceleration, as expected we see a significant reduction in the chamber pressure and thrust generated (Figs. 5.11, 5.12). However, by modestly increasing the spin rate from 18 rps to $22 \mathrm{rps}$, the thrust augmentation is restored while staying within 
the structural design limits of the rocket motor's casing (Figs. 5.13, 5.14).

Note also the rate of increase in sea-level thrust between the two approaches as shown in Figs. 5.4 and 5.6; the pintle has an almost linear thrust increase while the spinning design is much greater than linear and in Figs. 5.10 and 5.14, the curve appears to be an exponential rise. Comparing the thrust-time profile curve between spinning at $18 \mathrm{rps}$ and spinning at $22 \mathrm{rps}$, we see that the slope of the thrustcurve is much steeper. This would suggest that once the SRM is set to spinning at some nominal value (say 10 or $15 \mathrm{rps}$ ), the thrust profile is very responsive to small adjustments to the spin rate, potentially allowing for much more aggressive maneuvers.

Note that these thrust increases do not come for free; in the 22 rps case, it can be seen that the thrust duration of the rocket motor is reduced by over a second (i.e. over 10\%) in a nine-second firing. For interceptions and other critical maneuvers, this trade-off may be acceptable.

The number of g's experienced by the spinning motor is quite low; in the $10 \mathrm{rps}$ case at ignition, the g-force on the inner propellant surface is on the order of $7 \mathrm{~g}$ and at burnout (maximum inner propellant surface radius) the theoretical maximum is $26 \mathrm{~g}$ according to

$$
a=-\omega^{2} R
$$

where $\omega$ is $20 \pi \mathrm{rads}^{-1}$ at $10 \mathrm{rps}$ and $\mathrm{R}$ is $0.0175 \mathrm{~m}$ at the start and $0.0635 \mathrm{~m}$ at burnout. These relatively low normal accelerations are far below those modelled by Glick [12] and investigated by Broddner [16] where the throat area was presumed to be reduced by the spin-vortex induced in the central flow. Nevertheless, even 
at these relatively low acceleration levels, significant thrust augmentation occurred, suggesting that nozzle throat area reductions caused by spinning are not the primary factor in the burn rate augmentation observed. Assuming the opposite for the moment, one might also expect to see the thrust-time profile similar to that of the pintle-based design whereas it can be seen from Figs. 5.6, 5.10 and 5.14 that the thrust-time profiles (especially at the higher 18 and 22 rps spin rates) are different in shape and slope from the pintle-based approach (even after accounting for the two-step pintle-based thrust curves), further suggesting that the nozzle throat area flow reductions due to spinning would not be responsible for the predicted rates of thrust augmentation.

\subsection{Implementation Strategies for a Spinning SRM}

There are a number of ways that an SRM in a flight vehicle could be spun during different phases of the mission or flight profile. If spinning the entire airframe is desirable (or at least not detrimental) and the demand for burning rate augmentation occurs some time after ignition, then a variable incidence fin design as shown in Fig. 6.1 could be employed to start and stop the SRM spinning once sufficient forward velocity had been achieved. The flight computer would mix the trajectory inputs and the desired spin rate to deflect the variable incidence fins as required to achieve the necessary rate of spin and attitude control.

Alternatively, instead of spinning the entire airframe, the SRM could be spun independently (i.e. the SRM is mounted in the airframe on bearings) with a suitable 
Figure 6.1: Variable incident tail fins for inducing spin (shown deflected)

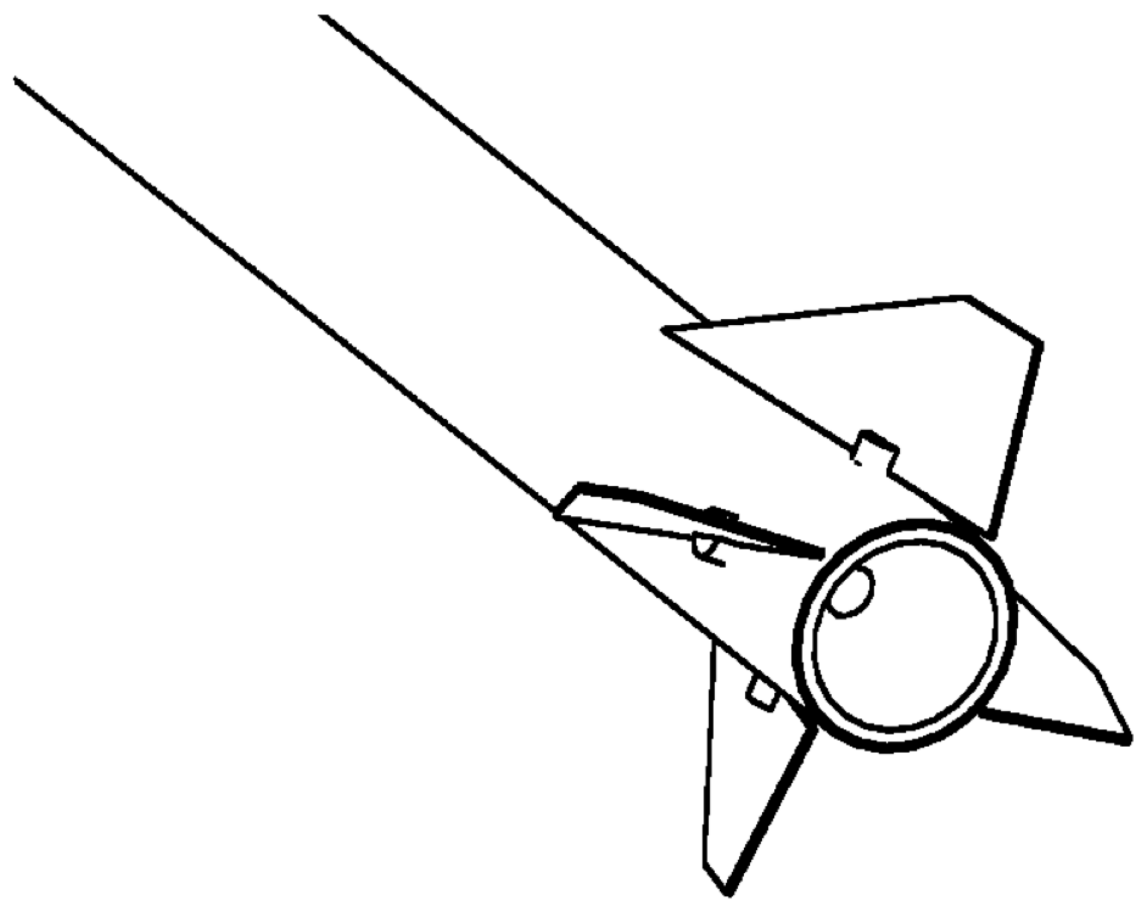

motor to spin and de-spin the SRM as required as shown in Fig. 6.2. In order to counteract the torque induced and to keep the airframe from spinning undesirably, variable incidence fins would also have to be employed.

Since maximum thrust is typically required at launch, another possibility is to spin the rocket up on the launch pad using an external motor as shown in Fig. 6.3. The extra weight of motor and batteries would not have to be carried as payload and there would be the added benefit of increasing the thrust at time in the mission profile where excess thrust is more desirable. This coupled with a slower regressing fuel grain would allow a solid rocket configured like this to have a higher initial 
Figure 6.2: Cutaway of spinning rocket with SRM rotated independently of the airframe

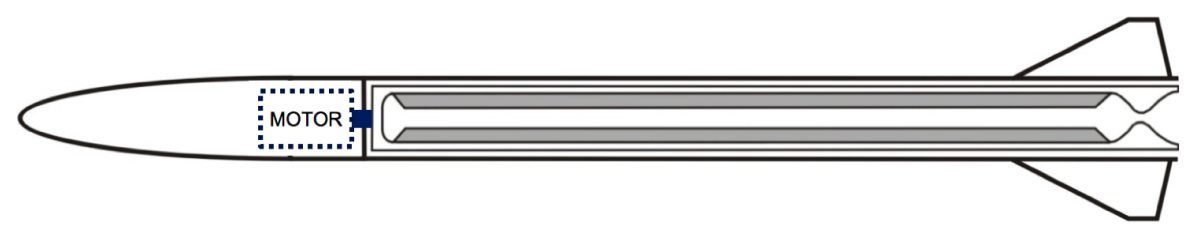

thrust off the launch pad and then potentially a longer sustaining phase with the added benefit that by locking the SRM to the motor casing after launch, the launch vehicle could also benefit from variable-incidence fin induced thrust augmentation later in the flight profile. For smaller rocket airframes, the entire flight vehicle could spin within an externally driven casing from which the rocket would be launched as shown in Fig. 6.4. 
Figure 6.3: Cutaway of externally spun SRM rotated independently of the airframe on the launch pad

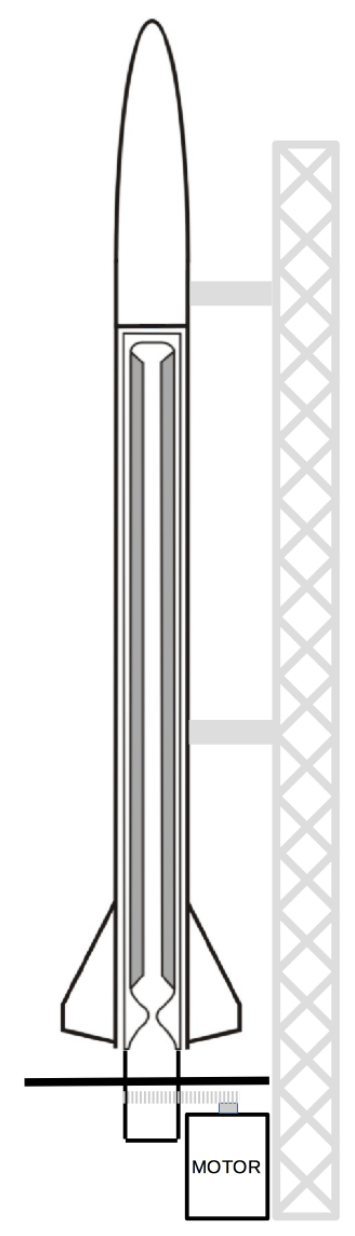


Figure 6.4: Schematic of an externally spun rocket airframe

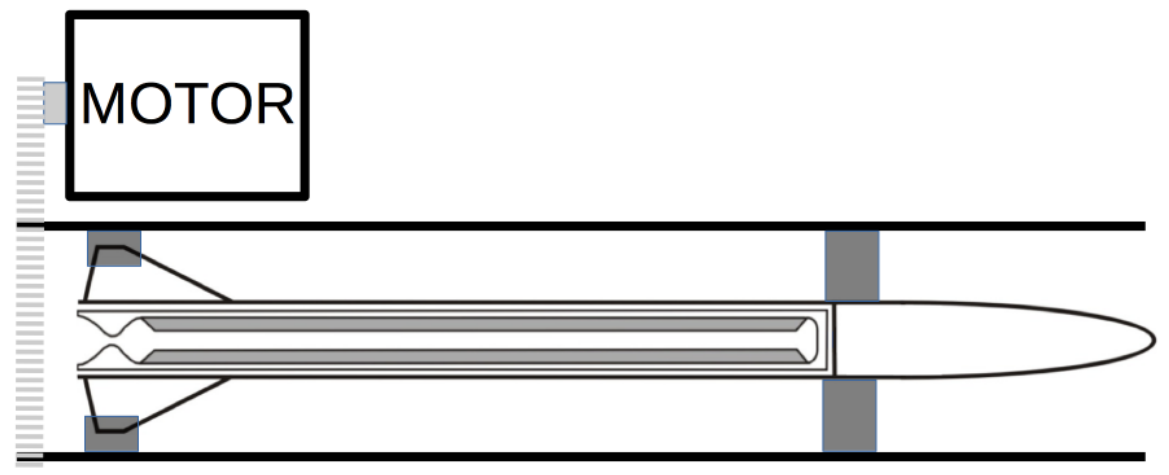




\section{Conclusion}

Comparing two types of propellant burning rate augmentation approaches for SRMs, the research conducted for this thesis suggests that spinning the solid rocket motor to induce a normal acceleration results in significantly higher burning rate augmentation compared to a variable area nozzle (i.e. pintle) approach without the parallel increase in combustion chamber pressure associated with pressure-dependent burning. For a given maximum chamber pressure, the results obtained here have indicated that substantially more thrust can be derived from spinning the SRM than by using a pintle (i.e. variable area nozzle). This advantage allows higher thrust for maneuvering or interception within a given airframe, or that the airframe could be lightened significantly without loss of performance. In the event of longitudinal accelerations on the airframe causing a reduction in burn rate augmentation, the SRM can simply be spun a little faster to restore the desired level of thrust.

Various mechanisms could be employed to induce spinning in a flight vehicle, depending on where in the mission thrust augmentation was most desirable and whether or not the entire airframe or just the SRM was to be spun.

Though there have been several studies and investigations of the effects on normal acceleration of the burning rate of solid propellant rocket motors, the majority of these have been to quantify and ultimately minimize the phenomena for existing and future SRM and vehicle implementations. Additional research opportunities 
exist to examine and quantify how to take advantage of normal acceleration-based burning rate augmentation and incorporate those ideas into more suitable propellant formulations for burning rate augmentation, and in turn designing solid rocket motors and flight vehicles to exploit this effect. 


\section{Considerations for Future Work}

The research presented in this thesis could be extended in a number of significant di-

rections. Many other types of propellants could be analyzed, as well as different sizes and lengths of SRMs to determine if there are any particular scale effects that need to be taken into consideration. A fully instrumented spinning test stand that would allow various SRM propellant compositions to be tested could be built to further generalize on the compressed combustion zone theory of burn rate augmentation. Existing off-the-shelf SRM motors could be tested as well as custom formulations. New propellant formulations especially produced for spin-augmented SRMs could be developed and tested. A small test vehicle with variable incidence fins could be constructed and flown to gather burning rate augmentation data in a real flight vehicle experiencing both normal and longitudinal accelerations and the latter's effect on the rate of augmentation (as per Figs. 2.5 - 2.8). As there has only been a small amount of work done to explore implementations of spin-augmented SRMs, there is considerable opportunity for future novel research. 


\section{References}

[1] Greatrix, D.R., Powered Flight: The Engineering of Aerospace Propulsion. Springer-Verlag, London Ltd, London (UK), 2012, pp. 323-343,426-427.

[2] Sutton, G.P., Rocket Propulsion Elements, 6th ed. John Wiley \& Sons, New York, 1992, pp. 366, 394.

[3] Greatrix, D.R., Gottlieb, J.J., "Erosive burning model for composite-propellant rocket motors with large length-to-diameter ratios," Canadian Aeronautics \& Space Journal, Vol 33, pp 133-142, 1987.

[4] Greatrix, D.R., "A Study of Combustion and Flow Behaviour in SolidPropellant Rocket Motors," University of Toronto, Toronto, ON, UTIAS Report No. 280, CN ISSN 0082-5255, 1987.

[5] Greatrix, D.R., Gottlieb, J.J., "Normal Acceleration Model for CompositePropellant Combustion," Transactions of the CSME, Vol. 12, No. 4, 1988, pp. 205-211.

[6] Greatrix, D.R., "Parametric Analysis of Combined Acceleration Effects on Solid Propellant Combustion," Canadian Aeronautics $\&$ Space Journal, Vol 40, No. 2, pp 68-73, 1994. 
[7] Greatrix, D.R., "Internal Ballistic Model for Spinning Star-Grain Motors", Journal of Propulsion and Power, Vol. 12, No. 3, May-June 1996.

[8] Greatrix, D.R. "Model of Prediction of Negative and Positive Erosive Burning," Canadian Aeronautics 63 Space Journal, Vol 53, 2007, pp 13-21.

[9] Greatrix, D.R., Wozney, C., Bockelt, M., "Alternative Thrust Modulation Techniques for Solid and Hybrid Rockets," 65th International Astronautical Conference, Space Propulsion Symposium, Toronto, ON, 2014.

[10] Heo, J., Jeong, K., Sung, H.G., "Numerical Study of the Dynamic Characteristics of Pintle Nozzles for Variable Thrust," Journal of Propulsion and Power, Vol. 31, No. 1, January - February 2015, pp. 230-237.

[11] Bastress, E. K., "Interior Ballistics of Spinning Solid-Propellant Rockets," Journal of Spacecraft and Rockets, Vol. 2, No. 3, May-June 1965, pp 455-457.

[12] Glick, R.L., "An Analytical Study of the Effects of Radial Acceleration Upon the Combustion Mechanism of Solid Propellant," Thiokol Corporation, Huntsville, AL, Contract NAS7-406, 1966.

[13] Anderson, J., Reichenbach, R., "An Investigation of the Effect of Acceleration on the Burning Rate of Composite Propellants," AIAA Journal, Vol. 6, No. 2, Feb.1968, pp. 271- 277.

[14] Lucy, M.H., "Spin Acceleration Effects on Some Full-Scale Rocket Motors," Journal of Spacecraft and Rockets, Vol. 5, No. 2, February 1968, pp. 179-183. 
[15] Sturm, E.J., Reichenbach, R.E., "An Investigation of the Acceleration-Induced Burning Rate Increase of Non-Metallized Composite Propellants," AIAA Journal, Vol. 8, June 1970, pp. 1062- 1067.

[16] Broddner, S., "Effects of High Spin on the Internal Ballistics of a Solid Propellant Rocket Motor," Aeronautica Acta, Vol. 15, 1970, pp 191-197.

[17] Northam, G.B.and Lucy, N.H., "On the Effects of Acceleration Upon Solid Rocket Performance," Journal of Spacecraft and Rockets, Vol. 6, April 1969, pp. 456-459.

[18] Northam, G.B., "Effects of the Acceleration Vector on Transient Burning Rate of an Aluminized Solid Propellant," Journal of Spacecraft and Rockets, Vol. 8, No. 11, 1971, pp. 1133-1137.

[19] Crowe, C.T., "A Unified Model for the Acceleration-Produced Burning Rate Augmentation of Metallized Solid Propellants," Combustion Science and Technology, Vol. 5, Jan. 1972, pp. 55-60.

[20] Fuchs, M.D., Peretz, A., Timnat, Y.M., "Parametric Study of Acceleration Effects on Burning Rates of Metallized Solid Propellants," Journal of Spacecraft and Rockets, Vol. 19, No. 6 (1982), pp. 539-544.

[21] Yang, P., et al., "Combustion Characteristics of Aluminized HTPB/AP Propellants in Acceleration Fields" in Solid Propellant Chemistry, Combustion and Internal Ballistics, Yang, V. et al., Eds. Reston, VA: AIAA Progress in Astronautics and Aeronautics, Vol. 185, 2000, pp. 907-919. 
[22] King, M.K., "Critical Review: Modelling of Acceleration Effects on Solid Propellant Combustion," AIAA Journal, Vol. 14. No 1, January 1976, pp. 18-25.

[23] Langhenry, M.T., Acceleration Effects in Solid Propellant Rocket Motors, AIAA/ASME/SAE/ASEE 22nd Joint Propellant Conference, AIAA Paper No. 86-1577, June 1986, Huntsville. 